\title{
RESPONSABILIDAD SOCIAL Y DIVERSIDAD DE LA COMUNIDAD
}

\author{
María del Rocío Brenes Alvarado \\ marobreal@ice.co.cr \\ https://doi.org/10.17979/redma.2009.01.02.4688
}

\section{RESUMEN}

En la era de la globalización de los mercados, el rol de las empresas evolucionó hacia una visión integral basada en la construcción de valor para sus distintos grupos de interés o stakeholders, sin cuyo apoyo la organización dejaría de existir.

Esta nueva manera de "ser" se conoce como Responsabilidad Social Empresarial o corporativa.

Con el presente trabajo se pretende lograr el objetivo de conocer el estado de desarrollo de la RSE en el mundo, en Latinoamérica y específicamente en Costa Rica.

\section{Palabras clave}

Responsabilidad Social Empresarial, empresas, Latinoamérica

\section{ABSTRACT}

SOCIAL RESPONSIBILITY AND COMMUNITY DIVERSITY

In the market's globalization era, business role has become into an integral vision based in value construction for its different stakeholders, without whose support the organization would cease to live.

This new way of being is known as Corporative Social Responsibility.

The present work intends to know the development degree the Corporative Social Responsibility has achieved in the world, in Latin America and specifically in Costa Rica.

\section{Keywords:}

Corporative Social Responsibility, Business, Latin America 


\section{I parte}

Introducción

Diversidad con la Comunidad

\section{II parte}

Filantropía Corporativa Mercadeo Social

\section{III parte}

Responsabilidad Social

En el mundo

En Latinoamérica

\section{IV parte}

Costa Rica: Situación actual Asociación empresarial para el desarrollo RSE Consultores Cecilia Mora Teoría vs. Práctica Horizontes 


\section{PARTE I:}

\section{Introducción a la Diversidad de la Comunidad}

\section{INTRODUCCIÓN}

En la era de la globalización de los mercados, el rol de las empresas ha dejado de delimitarse a la producción de bienes y servicios, para evolucionar hacia una visión integral basada en la construcción de valor para sus distintos grupos de interés o stakeholders, sin cuyo apoyo la organización dejaría de existir.

Se trata de un cambio en el paradigma de intereses de la empresa que ya no solo debe dar resultados y satisfacciones a corto plazo a sus accionistas, sino al conjunto de actores sociales: trabajadores y sus familias, sociedad civil, consumidores, sector público, proveedores, la sociedad en conjunto, etc. Esta nueva manera de "ser" se conoce como Responsabilidad Social Empresarial o corporativa.

Con el presente trabajo se pretende lograr el objetivo de conocer el estado de desarrollo de la RSE en el mundo, en Latinoamérica y específicamente en nuestro país. Identificar quien es nuestra sociedad, la diversidad de la comunidad y los posibles stakeholders. Evaluar los modelos conceptuales de RSE que tienen las asociaciones que están marcando la diferencia en responsabilidad social pero antes de esto, determinar la diferencia entre la filantropía corporativa, mercadeo social y responsabilidad social, y como los Relacionistas Públicos jugamos un rol de gran peso en el surgimiento y sostenibilidad como una herramienta de la RSE.

\section{Diversidad de la comunidad}

Responsabilidad social con la comunidad

En nuestra sociedad actual, la multiculturalidad es un gran negocio. Como árbitros de la comunicación de sus organizaciones, los profesionales de las 
relaciones públicas deben conocer las nuevas realidades multiculturales de la sociedad. El trato compresivo de la diversidad multicultural y la sensibilización ante los matices del lenguaje y las diferencias de estilo son ampliaciones lógicas de la responsabilidad social.

Una parte de importante de los programas de responsabilidad social corporativa hace referencia al voluntariado. Muchas empresas, que han donado sumas generosas a sus comunidades, han empezado a participar más directamente, fomentando de forma activa que sus ejecutivos y empleados se "remanguen" y se presenten como voluntarios para ayudar en sus comunidades.

Milton Friedman piensa que la Responsabilidad social única de una empresa consiste en ganar dinero y vender productos, de forma que se pueda contratar y pagar a los trabajadores. El servicio a la sociedad a través de la filantropía es una cuestión individual.

Para que una organización coexista pacíficamente con su comunidad, se necesitan tres cualidades en concreto:

1. Determinar qué sabe y piensa la comunidad de la organización.

2. Informar a la comunidad sobre el punto de vista de la organización.

3. Negociar o mediar entre la organización y la comunidad y sus miembros, en caso de que hubiera discrepancias significativas.

\section{Expectativas de las relaciones con la comunidad}

La comunidad varía dependiendo del tamaño y naturaleza del negocio donde se encuentre.

QUE ES LO QUE ESPERA LA COMUNIDAD

Contribuciones intangibles: 
a. Apariencia: Organizaciones que cumplan con normativas de seguridad, sobre la capa de ozono y sobre el medio ambiente general.

b. Participación: En cuestiones de la comunidad, como las funciones civiles, actividades recreativas y de parques, educación, bienestar y respaldo a las instituciones religiosas.

c. Estabilidad: Evolución según demanda de necesidades, sin excesos sobre servicios municipales.

d. Orgullo: Las organizaciones pueden ayudar a poner en el mapa una comunidad, por el simple hecho de estar ahí, suele contar con un valor añadido.

QUE ES LO QUE ESPERA LA ORGANIZACIÓN

a) Servicios municipales adecuados

b) Impuestos justos

c) Buenas condiciones de vida para sus empleados

d) Buena oferta de mano de obra para sus negocios y productos

\section{Objetivos de las relaciones con la comunidad}

Conseguir el respaldo de la comunidad es difícil, un instrumento útil es una política por escrito de relaciones con la comunidad que defina con claridad la filosofía de la dirección y como ve sus obligaciones para con la comunidad.

Los objetivos normales de relaciones con la comunidad pueden ser los siguientes:

1) Informar a la comunidad de las operaciones de la empresa: sus productos, el número de empleados, el tamaño de la plantilla, los pagos tributarios, crecimiento, balance social.

2) Corregir malentidos, responder las críticas de la comunidad.

3) Conseguir la opinión favorable de la comunidad.

4) Informar a los empleados y familias sobre las actividades $y$ acontecimientos de la empresa 
5) Informar a quienes trabajan en el gobierno local sobre las contribuciones de la empresa al bienestar de la comunidad y lograr el respaldo de la legislación afecte favorablemente al clima empresarial de la comunidad.

6) Descubrir Imagen corporativa por parte de la comunidad.

7) Establecer una relación personal ante la dirección y los líderes de la comunidad.

8) Respaldar programas de salud mediante contribuciones, tanto financieros como de empleados.

9) Contribuir a la cultura.

10)Ayudar a la educación de juventud y adultos.

11)Fomentar las actividades deportivas y recreativas ofreciendo campos de deportes y patrocinar acontecimientos deportivos.

12)Promocionar un mejor gobierno local y provincial, fomentar que los empleados colaboren con la municipalidad.

13)Ayudar a la economía de la comunidad comprando provisiones y los equipos a los distribuidores y fabricantes locales cuando sea posible.

14)Gestionar una empresa rentable de forma que se puedan ofrecer puestos de trabajos y salarios competitivos que aumenten el poder adquisitivo de la comunidad.

Cooperar con otras empresas locales para mejorar el bienestar económico y social mediante programas de conjuntos relaciones con la comunidad, financiados y dirigidos por las organizaciones participantes.

\section{Relaciones con la comunidad a través de Internet:}

En internet existe una $<<$ comunidad $>>$ virtual, aunque sus miembros de la comunidad vivan en cinco continentes distintos. El internet aunque parezca mecánico y frio, puede fomentar las relaciones humanas y el progreso entre comunidades y para la sociedad en general

\section{Cómo servir a comunidades diversas}




\section{MUJERES}

En el siglo XXI, las mujeres han dado grandes pasos para $<<$ nivelar el campo de juego >> entre sus cargos y retribuciones y los de sus homólogos varones. Los días de $<<$ trabajo para mamás $>>$ techos de cristal y $<<$ guetos de cuello de rosa >> cayendo rápidamente por doquier.

\section{AFROAMERICANOS}

Un área de frustración a la hora de mejorar la calidad de vida de los afroamericanos ha sido la práctica de las relaciones públicas.

\section{LATINOS}

En el 2050 se predice que los latinos serán la cuarta parte de la población estadounidense. Los latinos constituyen una potente fuerza política y económica.

\section{OTROS GRUPOS ÉTNICOS}

Además de los latinos, hay otros étnicos (asiáticos) que aumentan en importancia en el mercado gringo.

Los japoneses, chinos, coreanos, vietnamitas y otros asiáticos han ganado en importancia como consumidores y como votantes (USA). Los asiáticos y las personas provenientes de las islas del Pacifico representan el $4 \%$ de la población estadounidense.

\section{GAYS, PERSONAS DE LA TERCEDA EDAD Y OTROS}

El mercado gay es extremadamente atractivo para todo tipo de empresas. Además de los hombres y mujeres gay, las personas de la tercera de edad también se han convertido en una comunidad importante para los profesionales de RRPP y organizaciones que representan. La generación del babyboom ha 
pasado ya los 50 años de edad. Los RRPP debe ser sensibles s esta realidad y al hecho de que otras comunidades especiales de la sociedad demandarán cada vez más un trato especializado y unas comunicaciones especialmente dirigidas a ellas.

\section{Creciente defensa de la comunidad}

Grupos minoritarios tienen deseo de hablar y rechazar lo que consideren negativo. Una táctica popular para aumentar la concienciación del público, es la denominada: defensa mediática, que consiste en practicar las relaciones públicas sin recursos; consiste en utilizar a los medios de comunicación para atraer la atención y cambiar el orden establecido.

\section{Relaciones públicas no lucrativas}

Entre los principales campeones de la diversidad cultural en cualquier comunidad se encuentran las organizaciones no lucrativas. Las organizaciones sin ánimo de lucro actúan a favor de las necesidades sociales, educativas, religiosas y culturales de sus comunidades. El papel de las relaciones públicas en las organizaciones sin ánimo de lucro es tan importante que este sector constituye la principal fuente de empleo para los recién titulados en relaciones públicas.

El sector no lucrativo está caracterizado por diversas instituciones: hospitales, escuelas, agencias de bienestar social, instituciones religiosas, organizaciones culturales, etc. Las agencias sin ánimo de lucro quieren conseguir el apoyo popular a su misión y a sus programas mediante comunicaciones activas y abiertas. Sin embargo, a diferencia de las corporaciones, las agencias sin ánimo de lucro también intentan aumentar la participación de voluntarios en sus esfuerzos.

\section{Recaudación de fondos}


Fund- raising, la necesidad de conseguir dinero para respaldar operaciones, es la esencia de cualquier institución sin ánimo de lucro. Debe conseguirse de forma planificada y programada, para que tenga éxito una campaña de recaudación de fondos debe seguir los siguientes pasos básicos.

1) Identificar los planes y objetivos (Financieros genéricos) de la campaña. segmentar comunidad.

2) Organizar la recopilación de hechos. Relevancias que pueden afectar los fondos.

3) Reclutamiento de líderes.

4) Planificación y aplicación de sólidas actividades de comunicación. Publicity, se debe comunicar información de fondos a interesados.

5) Hay que revisar y evaluar periódicamente. Monitorear el programa, revisar estrategias a medida que se acerca el objetivo.

Puesto que muchos titulados en relaciones públicas acceden a instituciones en relaciones públicas acceden a instituciones no lucrativas, el conocimiento de las estrategias y técnicas de recaudación de fondos son especialmente importantes.

\section{PARTE II: \\ Filantropía Corporativa \\ Mercadeo Social}

FILANTROPÍA CORPORATIVA

"Es verdad que se ha considerado por mucho tiempo que los objetivos económicos y sociales son distintos y a menudo compiten entre sí. Pero ésta es una 
dicotomía falsa. Representa una perspectiva cada vez más obsoleta en un mundo de competencia abierta basada en el conocimiento. Las empresas no funcionan aisladas de la sociedad que las rodea. De hecho, su habilidad para competir depende considerablemente de las circunstancias de los lugares donde operan.

Michael Porter y Mark R. Kramer, 2002

\section{La ventaja competitiva de la filantropía corporativa}

MICHAEL E. PORTER Y MARK R. KRAMER ${ }^{1}$

Cuando se trata de filantropía, los ejecutivos con frecuencia se ven como si estuvieran atrapados entre críticos que exigen niveles siempre más altos de "responsabilidad social corporativa" e inversionistas que presionan mara maximizar utilidades en el corto plazo. La respuesta de muchas compañías ha sido tratar de hacer más estratégicas sus donaciones. Pero lo que pasa por filantropía estratégica casi nunca es verdaderamente estratégica y suele no ser particularmente efectiva como filantropía. La filantropía es usada cada vez más como una forma de relaciones públicas o publicidad para promover la imagen de una empresa por medio de auspicios de alto perfil.

Pero existe una manera realmente más estratégica de plantearse la filantropía. Las corporaciones pueden usar sus esfuerzos en beneficencia para mejorar su contexto competitivo, es decir, la calidad del ambiente de negocios en las localidades donde operan. Usar la filantropía para realzar el contexto competitivo hace converger objetivos sociales y económicos y mejora las perspectivas de negocio a largo plazo de una empresa.

$1 \quad$ Fuente 1: Artículo de Michael E. Porter y Mark R. Kramer de la revista Harvard Business Review. 
Preocuparse del contexto, le permite a una empresa no sólo dar el dinero, sino apalancar sus capacidades y relaciones en apoyo de causas benéficas. Eso produce beneficios sociales que exceden por mucho aquellos que resultan de donaciones de individuos, fundaciones y aun gobiernos.

Tomar esta nueva dirección requiere cambios fundamentales en la forma en que las compañías plantean sus programas de contribuciones. Por ejemplo, las inversiones filantrópicas pueden mejorar la educación y la calidad de vida en un lugar en formas que benefician a una empresa. Tales inversiones también pueden mejorar la competitividad de la compañía, al contribuir a la expansión del mercado local y ayudar a reducir la corrupción en el entorno de negocio local.

La adopción de un método enfocado en el contexto va a contrapelo de las prácticas filantrópicas actuales y requiere un método mucho más disciplinado que el prevalece hoy. Pero puede hacer que las actividades filantrópicas de una empresa sean mucho más eficaces.

\title{
MERCADEO SOCIAL
}

\section{Mercadeo hacia lo social: más mercadeo que social}

\author{
JUAN VIANEY GÓMEZ JIMENÉZ ${ }^{2}$
}

La satisfacción de la necesidad es el punto de partida de toda actuación en el Mercadeo, y esta creación de valor pasa a menudo no por las características esenciales del producto, sino por los componentes del llamado producto ampliado (Kotler, 1999). Esto es, los productos compiten no tanto por sus características técnicas sino por la imagen de la marca, el servicio postventa, el envase y por el producto emocional que está implícito en él, es decir, por aquel

$2 \quad$ Fuente 2: Artículo 2003. Economista de la Universidad La Gran Colombia y especialista en Finanzas de la Universidad EAFIT; Medellín, Colombia.

REDMARKA UIMA-Universidad de A Coruña - CIECID

Año 1, Número 2, (2009), pp. 111-182 
que recoge las sensaciones, vivencias y sentimientos (orgullo, simpatía, tranquilidad, etc.) que el producto o servicio despierta en el consumidor

Se debe integrar la acción social a la personalidad de la empresa; no debe estar orientada a los clientes sino a toda la sociedad en su conjunto. El mercadeo hacia lo social en todas sus presentaciones, debe ser formas de llevar a cabo la acción social, un componente más, no el objetivo institucional. Estas formas de mercadeo deben ser estrategias conducentes a cumplir con el objetivo institucional social, así como también lo serán las estrategias financieras, administrativas, productivas, de control, etc... La acción social no puede ser una técnica de Mercadeo. Debe entenderse que el Mercadeo hacia lo social es un proceso en el cual una empresa adopta sus decisiones de Mercadeo con un triple objetivo: la satisfacción del consumidor, el bienestar a largo plazo del consumidor y de la sociedad en su conjunto, y finalmente el interés empresarial (Kotler, 1999).

El mercadeo hacia lo social es una estrategia de mercadeo, por eso está condicionado al consumo. Si consumes "esto" eres solidario. Y si no, ¿soy insolidario?. La acción social no puede depender de sí se usa o no determinado producto o servicio. Tampoco es viable que la solidaridad de la empresa, sea cómoda y sin grandes compromisos, es decir, que "si el cliente compra cero, entonces ella ayuda cero".

El mercadeo hacia lo social es visto como algo bueno a priori pero con necesidades de control. Es una buena forma para sentirse bien consigo mismo mediante algo que se tiene que hacer de todas maneras (compras, internet). Es una forma cómoda de ejercer la solidaridad desde el carrito de la compra, desde el escritorio, desde casa, sin un compromiso mayor. ¿Termina acaso allí la responsabilidad del ciudadano/consumidor? ¿Así como algunas empresas lavan con el mercadeo hacia lo social algunas culpas, los consumidores limpian su conciencia solidaria? Será necesario que también se establezcan principios clave, otras cinco Ces, para el compromiso social de los ciudadanos?. 
Seguramente si se trata de acciones sociales como parte de las políticas y objetivos de la empresa y no de campañas de mercadeo, se evitará además de usar imágenes degradantes como ha ocurrido en algunos casos, las palabras clave empleadas en los slogan de los anuncios y que buscan estimular el consumo de los productos: "gracias", "colabora", "solidaridad", "necesita", "contribuye" o "humanitario". No precisamente palabras que motivan a cambios, a combatir injusticias o a atacar las causas estructurales de la pobreza. Estas palabras parecieran motivar más a una ayuda puntual y de carácter monetario. Apelan directamente a los sentimientos del receptor.

Aún está por garantizar en mejor forma la participación del ciudadano en este tipo de campañas. Asegurarle que realmente existe un compromiso con las causas sociales y que estas campañas no son una respuesta comercial a demandas marginales, es decir, que este paquete de actividades se desprende de políticas sociales implícitas y explícitas dentro de la empresa, como una clara manifestación de que la acción social hace parte del quehacer cotidiano.

La intervención de Instituciones con reconocida solvencia moral y la conformación de comités integrados por representantes de las comunidades que intervienen generalmente en estas campañas, podrían convertirse en "garantes" ante la opinión pública. El otorgamiento de permisos o de sellos como el de "acción solidaria" en España, son una de las formas de evitar errores de presentación de campañas o el inadecuado uso de los dineros recogidos. Pero debe cuidarse de no volver este distintivo en otra forma de diferenciación de las empresas y de sus marcas.

Está pendiente por evaluar el impacto social y económico de las campañas de mercadeo hacia lo social tanto para las causas como para las empresas. Es claro que las campañas han solucionado problemas temporales en algunas comunidades, como también es claro que no han aportado creando bases para cambios. También es indiscutible que para las empresas han generado beneficios importantes, pero tampoco se ha podido cuantificar con exactitud 
cómo han repercutido en ventas o mercado una campaña. Al menos los resultados no se dan a conocer.

Las campañas de mercadeo hacia lo social no son ni buenas ni malas, depende de la utilización que empresas, ONGs y consumidores hagan de ellas. Esta puede ser la vía más rápida para dar inicio a una cultura de acción social a partir de las empresas. En la medida en que muchas empresas del mundo desarrollen programas de mercadeo hacia lo social, y se continúe con el incremento de empresas que involucran la acción social como parte de su actuar diario, más cerca se estará de dar un segundo paso en este largo recorrido de hacer un mundo menos desequilibrado. Debe considerarse eso sí, que los esfuerzos por promover los objetivos sociales a través de la redistribución de las rentas, las subvenciones y la distorsión del mercado suelen fracasar y cuestan mucho dinero (PORTER, 1999). La formación y capacitación deben ser las directrices principales; el apoyo debe canalizarse hacia el desarrollo, hacia un desarrollo sostenible.

Además de las preocupaciones e interrogantes que quedan planteadas, los estudios que se han realizado en Europa y en América, lógicamente en países industrializados, no evidencian por parte de consumidores y de empresas, un interés amplio y marcado por contribuir a causas sociales de países del tercer mundo, a no ser que sea en momentos de catástrofes. Las expectativas varían según el país, pero siempre se consideran 3, 4 y hasta 5 problemáticas propias por encima de la ayuda al desarrollo de otros países.

La pugna conceptual por si a la empresa le corresponde también la acción social continuará. Puristas de uno y otro lado defenderán sus posiciones encontrando múltiples justificaciones. Inclusive algunos optarán lo social como una forma de alcanzar lo económico. Quienes más rápido incorporen lo social en su quehacer diario, así como ocurrió con lo ambiental y la calidad, menos dificultades para permanecer en el futuro tendrán. 
La empresa que aún considere lo social como algo marginal, puede acometer una "pequeña inversión" en conocer la problemática social y las expectativas de su entorno y analizar los distintos tipos de beneficio que se pueden generar. Seguramente encontrará que al incorporar la acción social en su proceso, habrá encontrado un eslabón más de la cadena que genera riqueza, riqueza para la comunidad.

PARTE III

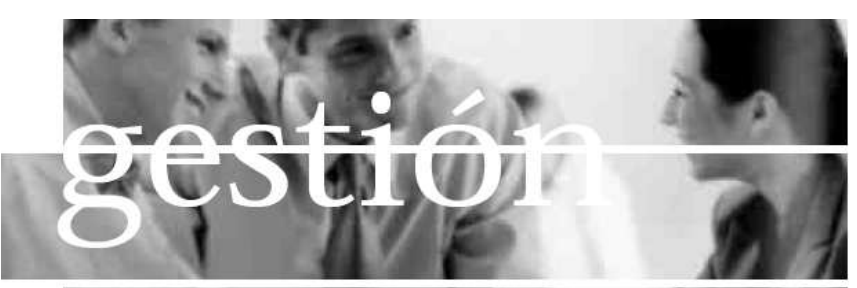

Responsabilidad social en el mundo. En Latinoamérica

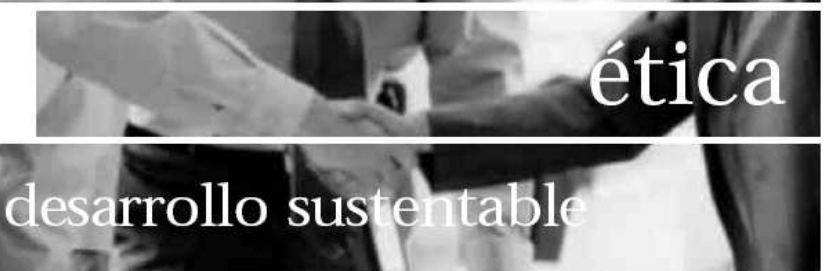

RESPONSABILIDAD SOCIAL EN

EL MUNDO

En los negocios del siglo XXI y la economía mundial se entiende por responsabilidad social:

La Responsabilidad social es lograr éxito comercial en formas que honren los valores éticos y respeto por la gente, comunidades, y el ambiente natural; Abordando las expectativas legales, éticas, comerciales, y otras que la sociedad tiene de los negocios, y haciendo decisiones que balancean de modo justo las demandas de todos los públicos de interés.
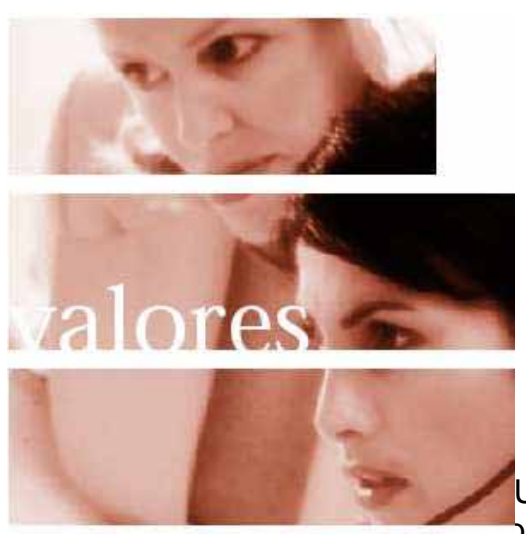

La responsabilidad es un concepto en el cual las áreas productivas integran consideraciones sociales y ambientales en sus operaciones empresariales y en las relaciones con sus interesados de una manera voluntaria". 
COMISIÓN EUROPEA

Responsabilidad social empresarial es el compromiso continuo de los negocios para conducirse éticamente contribuir al desarrollo económico mientras mejoran la calidad de vida de sus empleados y sus familias, de la comunidad local y de la sociedad en general".

WORLD BUSSINESS COUNCIL FOR SUSTAINABLE DEVELOPMENT (WBCSD)

"La empresa del futuro no podrá limitarse a ser una mera explotación económica en el sentido tradicional del concepto. Adquirirá un mayor protagonismo en la sociedad en tanto que sea responsablemente social, lo cual incorpora aspectos como que sus productos y servicios sean aceptados por los ciudadanos, cumpla estrictamente la normativa vigente, sus directivos tengan un comportamiento ético intachable, conceda una importancia adecuada a la relación de sus empleados, sea respetuosa con el medio ambiente o apoye a las comunidades más desfavorecidas en las que opera". FUNDACIÓN EMPRESA Y SOCIEDAD, ESPAÑA.

LA EVOLUCIÓN DE LA RESPONSABILIDAD SOCIAL, específicamente la empresarial o corporativa se puede visualizar en tres generaciones Como lo muestra la siguiente figura: 


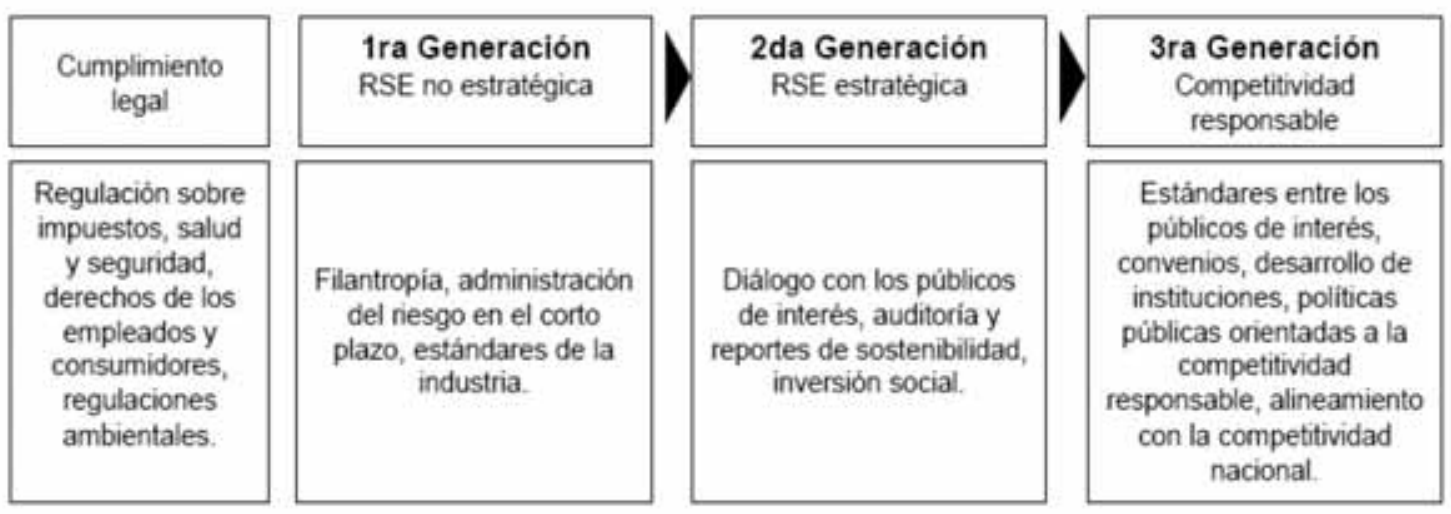

FUENTE: LA RSE EN EL MUNDO: CONCEPTOS GENERALES Y EVOLUCION. FORO-TALLER COLABORADORES. INCAE 17 DE JULIO 2008.

Algunos de los ORganismos QUe HAN SIDO PARTE DE LA EVOLUCión de la responsabilidad social y pilar para su desarrollo en la actualidad, se encuentran:

\section{Organización para la cooperación y el desarrollo económico}

Su principal aporte fue el libro: Directrices para las empresas multinacionales, documento publicado en 1976 y actualizado en ocasiones sucesivas, la última en el 2000, que recoge recomendaciones sobre diversas materias: empleo, relaciones laborales, medio ambiente, lucha contra la corrupción, intereses de los consumidores, ciencia y tecnología, competencia y fiscalidad

\section{Banco Mundial}

Su principal aporte: Oficina de prácticas de responsabilidad social corporativa, el cual es un órgano que aconseja a los gobiernos de los países en vías de desarrollo acerca de aquellas políticas validas para fomentar un comportamiento responsable por parte de las empresas.

Las medidas propuestas:

- Legislativas

- De incentivos

- De colaboración

- De aval (apoyo a las instituciones a las medidas de RSC) 


\section{Naciones Unidas}

El 31 de enero de 1999, en el marco del Foro económico mundial de Davos, el secretario general de las Naciones Unidas Kofi Annan animó a los líderes económicos a unirse a una iniciativa denominada Pacto Global.

El objetivo de de esta iniciativa es la creación de una red integrada de trabajo entre las compañías, la ONU y sus organizaciones sectoriales, las ONGS globales y las uniones sindicales internacionales que fomente el cumplimiento de diez principios universales básicos formulados por las naciones unidas cuatro ámbitos: derechos humanos, estándares laborales, medio ambiente y lucha contra la corrupción.

\section{Unión Europea}

El Libro Verde:

"Fomentar un marco europeo para la Responsabilidad social de las empresas" (18 de julio 2001).

Este documento establece las líneas maestras en torno a las cuales ha de girar el debate sobre la Responsabilidad social corporativa en la unión europea. Anima a las empresas con comportamientos socialmente responsables a que traten de publicitar este hecho. Considera que el resto de agentes sociales son responsables a la hora de exigir a las empresas la asunción de prácticas que redunden positivamente en el bienestar social.

La comisión europea, creadora del Libro Verde, trata de lograr un enfoque integrador a través de los siguientes puntos:

- Gestión integrada de responsabilidad social: Es necesario formar a directivos y trabajadores en materia de ética y responsabilidad. 
- Informes y auditorías sobre la responsabilidad social: Utilización de normas internacionales aceptadas.

- Calidad del trabajo: Se recoge la necesidad de ampliar el diálogo social a las cuestiones sociales, medioambientales y gestión de recursos humanos.

- Etiquetas sociales y ecológicas: Incrementar transparencia en relación a etiquetas sociales y ecológicas a través de un control continuo de los lugares de trabajo efectuado de acuerdo a normas acordadas.

- Inversión socialmente responsable (ISR): Es necesario que los mercados sean consientes de la rentabilidad potencial de este tipo de inversiones.

FUENTE: ARTICULO DE LA RESPONSABILIDAD SOCIAL, CORPORATIVA DE LA UNON EUROPEA $Y$ ARTICULO DEL. INSTITUTO ARGENTINO DE RESPONSABILIDAD SOCIAL.

\section{Mecanismos que han estimulado la difusión de la RSE en el mundo}

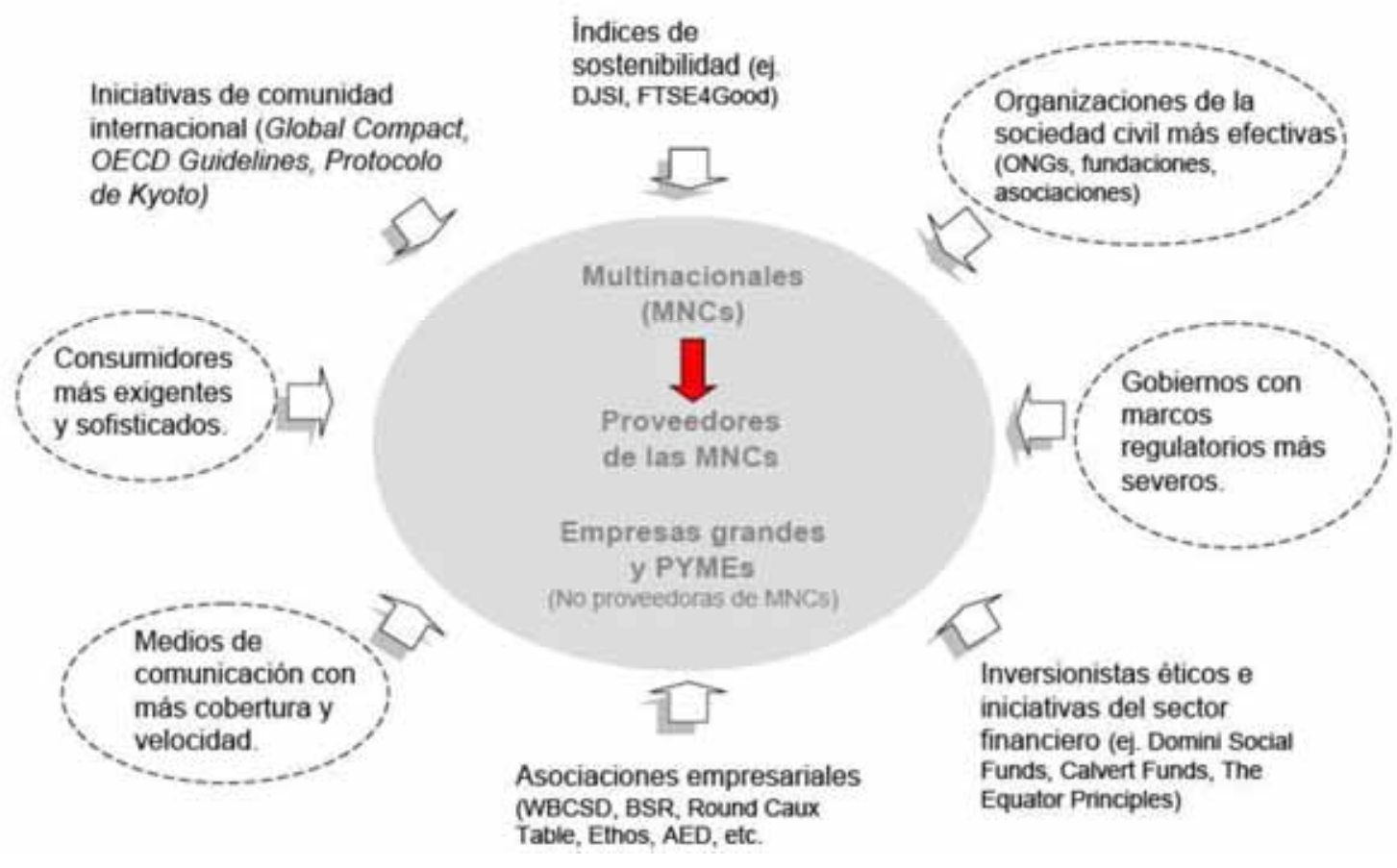

FUENTE: ENRIQUE OGLIASTRI, JULIANO FLORES, ARTURO CONDO, ET AL "MANUAL DE RESPONSABILIDAD SOCIAL DE LA EMPRESA: EL OCTAGONO", INCAE (FORTHCOMING).

RESPONSABILIDAD SOCIAL EN LATINOAMERICA 
En el nuevo paradigma de negocios se entiende por la responsabilidad social como parte de la obligación de toda organización para la sociedad en conjunto, tanto en micro, medianas y grandes empresas. Algunas definiciones de Responsabilidad Social, empresarial o corporativa en Latinoamérica son:

INSTITUTO ETHOS

Responsabilidad social es un forma de gestión que se define por la relación ética con todos los públicos con los que ella se relaciona, y por el establecimiento de metas empresariales compatibles con el desarrollo sustentable de la sociedad; preservando recursos ambientales y culturales para las generaciones futuras, respetando la diversidad y promoviendo la reducción de las desigualdades sociales.

INSTITUTO ETHOS DE EMPRESAS Y RESPONSABILIDAD SOCIAL, BRASIL

El concepto de Responsabilidad Social en Responsabilidad Social alude a un modelo estratégico de gestión de la compañía, que contempla los impactos económicos, sociales y ambientales derivados de la actividad empresarial. Implica por lo tanto el compromiso renovado de las empresas con la comunidad, con su entorno y sus públicos de interés".

INSTITUTO ARGENTINO DE RESPONSABILIDAD SOCIAL EMPRESARIAL.

Responsabilidad Social es la responsabilidad que tienen las personas, instituciones y empresas para contribuir al aumento de bienestar de la sociedad (local y global. Es la contribución al desarrollo humano sostenible, a través del compromiso de confianza con sus empleados y familias, la sociedad en general y la comunidad local en pos de mejorar su capital social y calidad de vida".

FUNDACIÓN PROHUMANA CHILE

\section{Situación en la RSE en Latinoamérica: hacia un desarrollo sostenible}

En un estudio realizado por la Red Interamericana de empresas RSE, alianza de instituciones académicas y de investigación vinculadas a esta temática y 
con la colaboración del Ministro de Economía de Holanda, que hizo posible la recopilación de los informes de los diez países que incluye dicho estudio; Argentina, Brasil, Chile, Colombia, Costa Rica, El Salvador, México, Panamá, Perú y Uruguay.

Fue posible comprobar que el sector privado, ha ido tomando conciencia de la necesidad de preocuparse por responder a las necesidades sentidas de la población y contribuir a aumentar su calidad de vida, pues requiere de sociedades estables para producir y prosperar.

Un desafió fundamental resulta ser la plena la incorporación de las PYMES a la RSE, las que juegan un rol fundamental en la economía y sociedad de la región, especialmente como generadoras de empleo y riquezas. Los gobiernos están dando fluidez a la tendencia del concepto de las alianzas de colaboración públicoprivada.

Una señal de mercado muy relevante es el desarrollo de la norma ISO 26000 de Responsabilidad social, que permitirá hacer converger la multiplicidad de estándares existentes y facilitar su implementación en las empresas.

Es importante analizar las tendencias, desafíos y oportunidades de dos países que están marcando grandes pautas en el desarrollo sostenible de la RS en Latinoamérica nos referimos a Argentina y Brasil. Sin embargo hay que dejar en claro que los demás países Latinoamericanos también están en un proceso de dejar atrás la filantropía para dar desarrollo a la Responsabilidad Social, pero les falta ser más competitivos y una concreta colaboración del gobierno, así mismo una visión menos comercial y más humanística.

\section{ARGENTINA}

"Un país que despierta la responsabilidad social" 
La profunda crisis socioeconómica, política e institucional que sacudió a Argentina a mediados del año 2001 es clave para entender el proceso de afianzamiento del movimiento de Responsabilidad Social empresarial (RSE) en el país. La crisis opero como un gatillador fundamental para despejar la inercia e impulsar al empresariado local a la acción. Es decir, suscito en algunas compañías y emprendedores la reflexión acerca del rol que les compete cumplir en la sociedad.

La sociedad Argentina en la actualidad demanda una gestión responsable frente al medio ambiente y la sociedad. El estado Argentino tiene un pendiente, el cual representa minimizar la debilidad y fragilidad institucional que contribuye a sostener un entorno de informalidad y corrupción, lo que impide una buena retroalimentación de información sobre RSE entre los sectores públicoprivado.

En el año 2001 nace el Instituto Argentino de Responsabilidad Social empresarial, que tiene como fin la promoción de la RSE a nivel nacional, en conjunto con redes de información como el Instituo Ethos de Brasil, país donde el tema esta mas difundido entre el sector empresarial y por consiguiente ha alcanzado un mayor grado de desarrollo y especialización. Lo concreto es que muchos han comprendido que, "no existen compañías exitosas en sociedades fracasadas" y han comenzado a tomar cartas en el asunto.

BRASIL

"Compromiso con el desarrollo sustentable" 
La Responsabilidad Social empresarial (RSE) en Brasil se fortalece y gana dimensiones más concretas en la década de los 90 por la vía de la movilización de grupos de empresarios, ejecutivos, consultores y representantes de ONGS que buscaban debatir en torno al tema y estimar sus primeras iniciativas, así como evaluar sus contribuciones potenciales. En consecuencia, la RS no nace por iniciativa del gobierno como en otros continentes sino por los empresarios Brasileños.

La ventaja competitiva de Brasil en ámbitos de RSE, radica en la disposición del país en erradicar la pobreza, disposición observada con frecuencia por ejemplo en la cumbre más reciente de la G8 realizada en Davos, Suiza, donde Brasil propuso la creación de un fondo internacional destinado exclusivamente para el combate del hambre y la pobreza.

En el universo empresarial, se observan relevantes cambios en la forma de gestión de las compañías Brasileñas. Se puede citar concretamente avances tales como:

- Brasil está entre los países con el mayor número de bancos que adhieren los principios de Ecuador (www.ifc.org/equatorprinciples).

- La bolsa de valores de Sao Paulo (Bovespa) está en vías de lanzar el índice de Sustentabilidad Empresarial

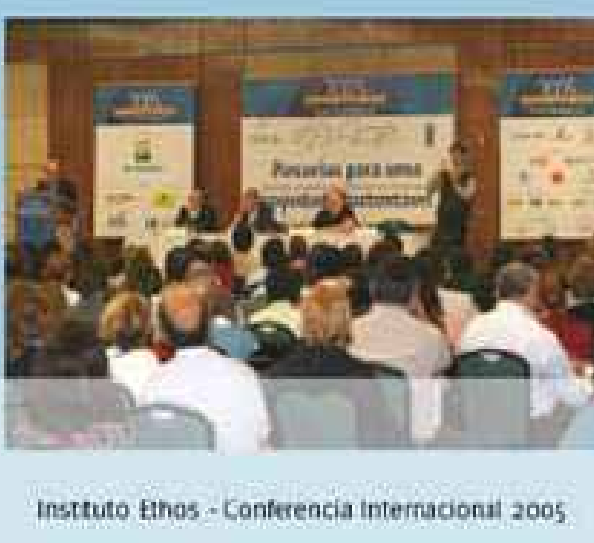
(ISE), índice de acompañamiento de desempeño de acciones para empresas que adoptan criterios de RSE, como el Dow Jones Sustainability Index y el FTSE4GOOD Index.

- Es creciente el número de instituciones financieras que incluirán cláusulas socios ambientales en contratos de adhesión.

- Actualmente, 73 empresas tienen la certificación SA 8000, social accountability. Brasil tiene el cuarto lugar de esta certificación, solamente superado por Italia, China e India. 
- 150 empresas Brasileñas están comprometidas por el Pacto Global de las naciones unidas (ONU).

A pesar de los avances anteriormente presentados y de las señales de que se encamina en la dirección correcta, los resultados agregados para la nación aún no acompañan la velocidad de los individuos y del planeta.

\section{Manual de primeros pasos en RSE}

EL instituto Argentino de Responsabilidad Social empresarial (IARSE) publico de la adaptación en español del Instituto ETHOS de Brasil el Manual de Primeros Pasos en RSE. El cual resume la mayoría de práctica que toda empresa que se quiere hacer llamar socialmente responsable debe aplicar con sostenibilidad. El manual nos indica 6 indicadores que una empresa debe evaluar y velar por que el desarrollo de las respectivas prácticas laborales sean responsables equitativamente con la sociedad. 


\section{Primeros pasos}

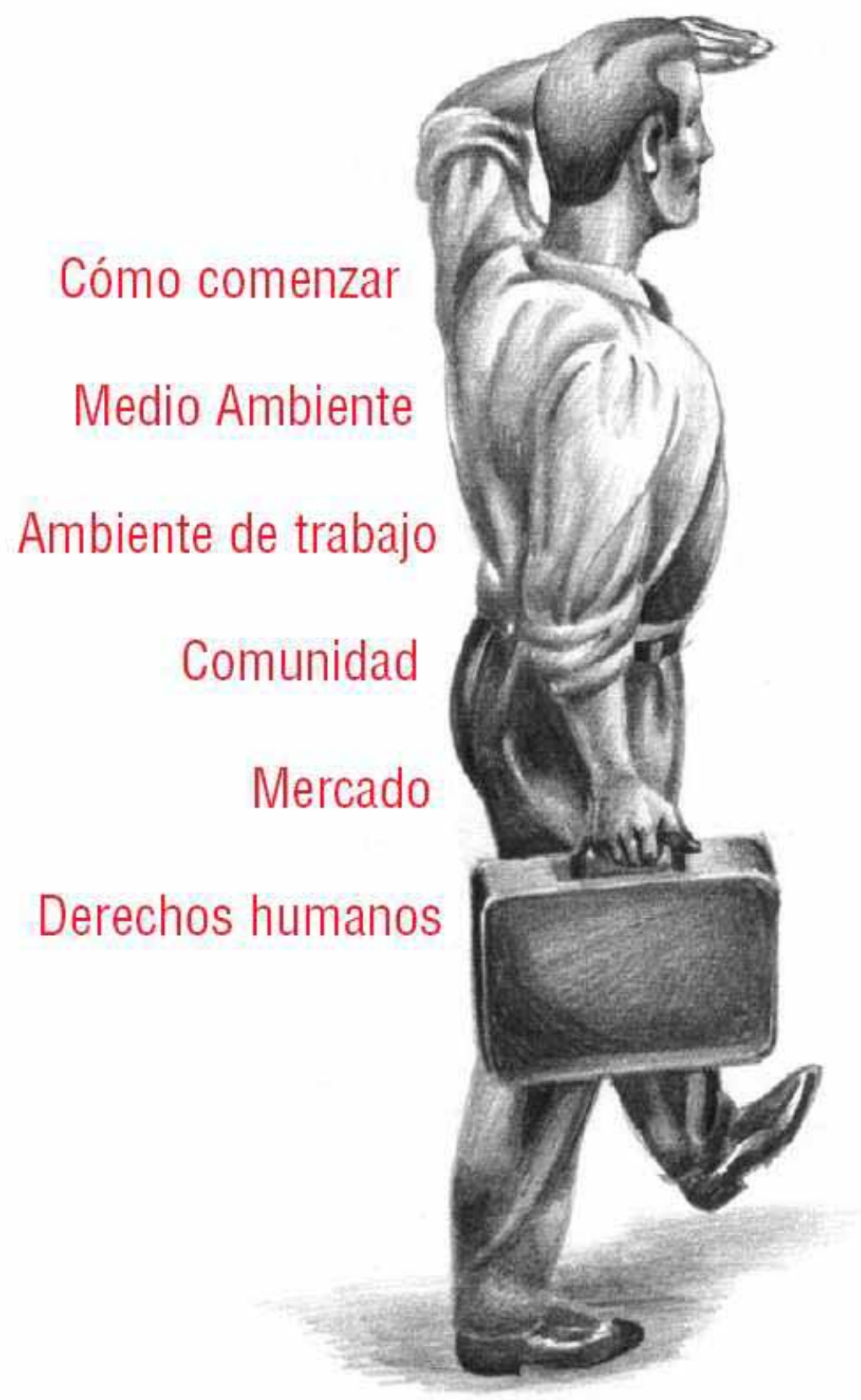

COMO COMENZAR

\section{VISIÓN Y MISIÓN}


Cree una declaración de misión y visión: Especifica que la empresa socialmente responsable procurara dar valor agregado a todos los involucrados en el ambiente empresarial: accionistas/propietarios, empleados, clientes, proveedores comunidades, y propio medio ambiente.

Comparta su declaración: Comparta inicialmente con los colaboradores su declaración y en una segunda fase cambien lo que considere apropiado.

Integre la misión a la visión: Dele vida a su visión para que sea más que un simple papel.

Revise periódicamente la declaración: Considere una evaluación anual a como vaya acercándose a sus metas.

ETICA

Identifique y articule valores éticos claros: Cuando esté bien hilvanada e implementada, una declaración de valores éticos especificara la forma en la cual la empresa administrara los negocios. Normalmente las personas consideran que la honestidad, compromiso, integridad, lealtad, solidaridad, compasión, respeto al prójimo, son los valores que pueden ser vistos como éticos.

Use valores éticos para resolver dilemas: Las soluciones de conflictos entre los distintos públicos de la organización tienen que ser compatibles con los valores éticos.

Capacite en Ética a sus colaboradores: El éxito radica en la revisión periódica de los valores éticos.

Cree un ambiente abierto a la discusión: Explique la coherencia de las decisiones tomadas en la empresa y los valores, sea abierto. 
Incorpore la ética a la evaluación del desempeño de los colaboradores: Vincule certificaciones a los empleados por actitudes éticas.

\section{AUDITORÍA Y RENDICIÓN DE CUENTAS}

Audite regularmente el desempeño de la empresa: Esta evaluación puede ser tan informal como preguntar: ¿Cómo me está yendo?, o puede involucrar un proceso formal que incluya entrevistas, cuestionarios $u$ otros recursos. Un modelo de "lista de validaciones".

Obtenga retroalimentación de sus primeras auditorías: Incorpore opiniones y comentarios recibidos al texto final del informe de validación.

Comparta los resultados de la Auditoría: Primero comparta los resultados con grupos seleccionados y, en una segunda instancia, hágala pública. 


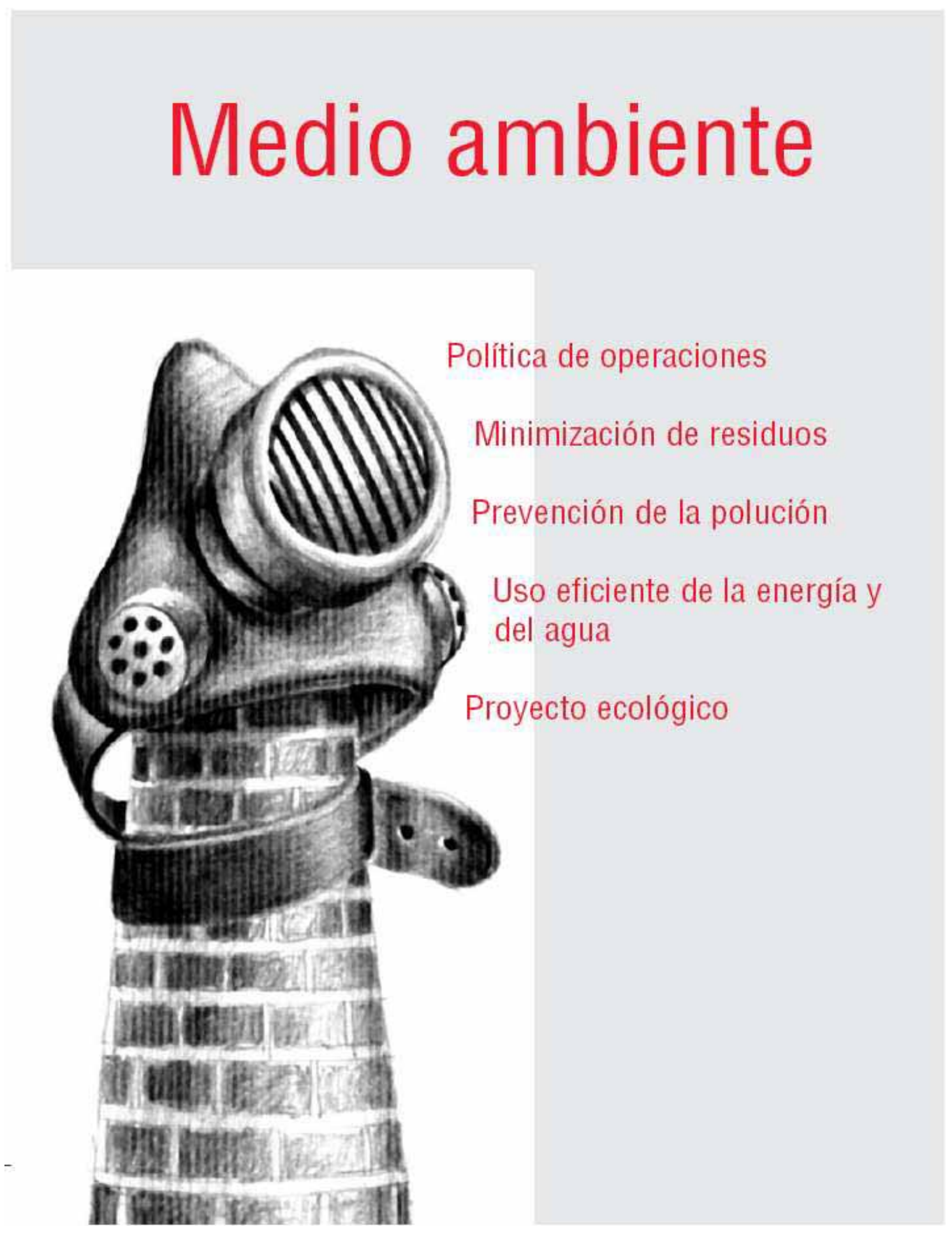

MEDIO AMBIENTE

POLÍTICA DE OPERACIONES

Adopte principios de protección al ambiente: Establezca compromisos y patrones ambientales para su empresa que incluyan metas formales. 
Haga una auditoría ambiental: Haga un inventario informal o formal de los residuos utilizados por su empresa y del residuo generado.

Establezca una política ecológica de compras: Especifique el compromiso de la empresa de priorizar la compra de productos ambientales amigables.

Motive a los colaboradores en temas ambientales: Nomine periódicamente a un "campeón verde" que demuestre el compromiso de su empresa con el medio ambiente.

MINIMAZIÓN DE RESIDUOS

Cree un programa de reciclaje: Anime a sus colaboradores a presentar sugerencias para la reducción de residuos.

Reduzca el consumo de papel: Implemente un uso racional del mismo, utilizar más el correo electrónico.

Use productos de papel reciclado: Elija papel con el mayor índice de material reciclado.

Compre productos reciclados: Privilegie la compra de productos reciclados, reformados verificando si compiten favorablemente en precio, desempeño, y calidad del producto.

Done el excedente de mobiliarios y equipamientos: Relaciónese con organizaciones de beneficencia e infórmese sobre el tipo de equipos que aceptan y necesitan.

Declare los excedentes de materiales reciclables. Evite el uso de productos que generen residuos. Alquile los equipamientos que use en forma ocasional. 
PREVENCIÓN DE LA POLUCIÓN

Reduzca el uso de productos tóxicos: Haga una evaluación de todo el espacio físico.

Realice la disposición segura de sustancias tóxicas: Asegure el descarte de los materiales tóxicos, incluyendo aquellos que parecen inofensivos.

Use productos de limpieza no tóxicos.

Haga una inspección ambiental: Para la impresión de documentos de su empresa, use productos y procesos de impresión menos perjudiciales para el medio ambiente.

USO EFICIENTE DE LA ENERGÍA Y EL AGUA

Haga una auditoría de los usos de la energía: Contacte una consultora de energía y solicite una auditoría.

Use sistemas de iluminación inteligente: Existen innumerables productos alternativos en el mercado que pueden proporcionarle un significativo ahorro en el consumo de energía y mejor iluminación.

Aplique técnicas eficientes para administrar el uso de la energía.

Promueva el uso de otras tecnologías eficientes para reducir el consumo de energía.

Promueva el uso de transporte alternativo.

Considera la posibilidad del trabajo a distancia: Cuando sea posible permita que sus colaboradores trabajen desde su casa un día a la semana. 
Haga un buen mantenimiento del sistema de climatización: Controle que la limpieza de los filtros se realice regularmente.

Mantenga una buena flota de vehículos ambientalmente amigables: Haga la adquisición o leasing de vehículos que presenten mayores índices de economía de combustible.

Localice y arregle regularmente las pérdidas de agua. Instale dispositivos para economizar agua. Reduzca el uso de agua en áreas externas: Ahorre agua en jardinería.

PROYECTO ECOLÓGICO

Crea un sistema de reciclaje: Trabaje con los clientes de manera que retornen productos retornables.

Utilice técnicas de construcción ecológicamente correctas: Proyectos de construcción ambientalmente correctos pueden reducir el costo total del ciclo de vida de la edificación.

Examine el diseño de productos y servicios: Analice los productos y servicios desde un punto de vista ecológico con el objetivo de reducir desperdicios.

Trabaje asociado con proveedores y clientes: Considera la posibilidad de proveer servicios que vayan mas allá de la venta de producto 


\section{Ambiente de trabajo}

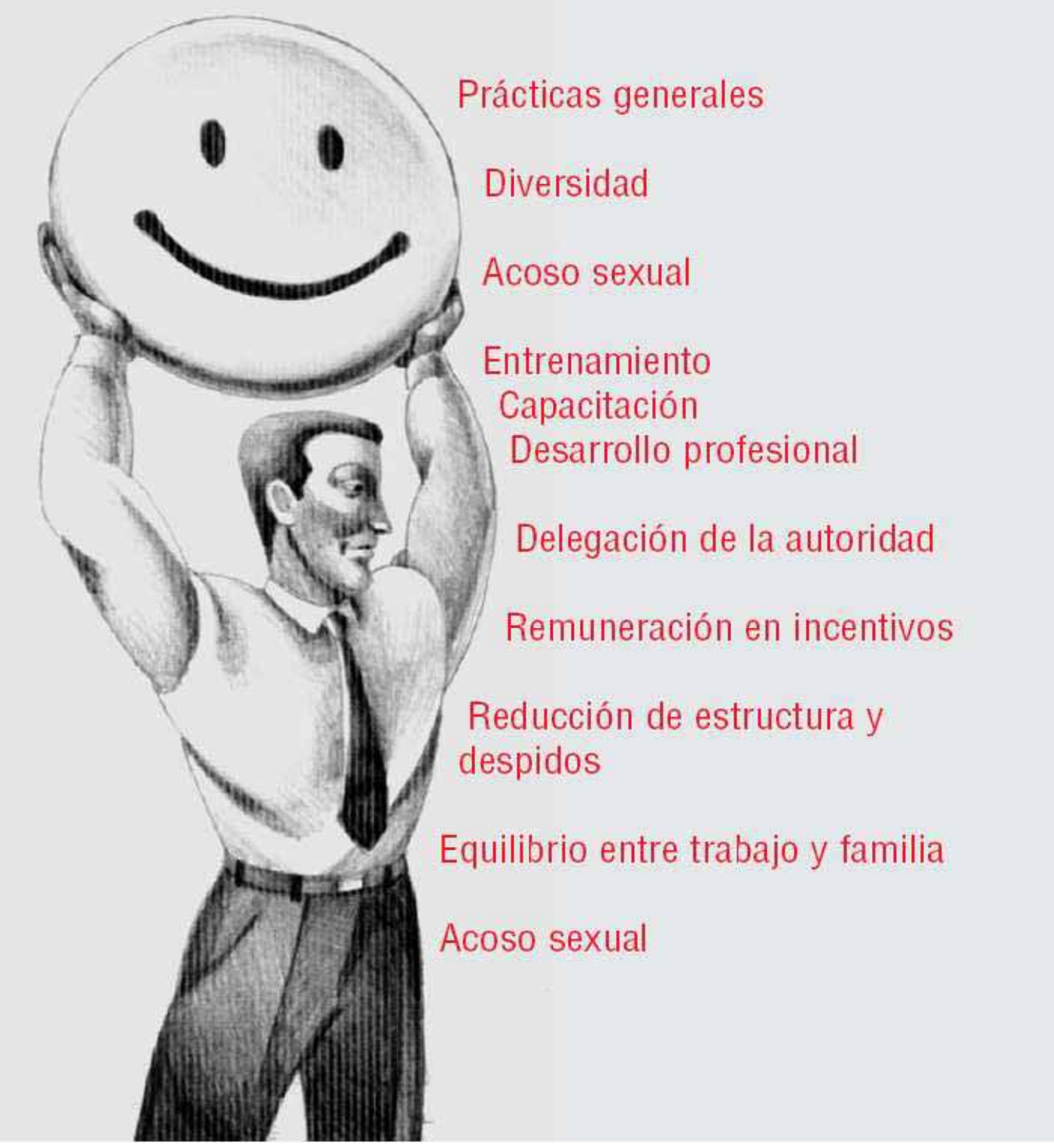

AMBIENTE DE TRABAJO

PRÁCTICAS GENERALES 
Publique y distribuya una guía de comportamiento entre sus colaboradores: Notifique sobre directivas y prácticas importantes adoptadas por la empresa.

Apoye nuevas ideas y comentarios: Cree un ambiente de trabajo que aliente al personal a aportar nuevas ideas y opiniones sobre la empresa y sus directivas.

DIVERSIDAD

Incorpore diversidad como un valor esencial adoptado por la empresa: Muchas de las declaraciones de diversidad incluyen referencias específicas al carácter no discriminatorio en relación a sexo, edad, religión, ascendencia, nacionalidad, estado civil, orientación sexual, discapacidad física, mental y condiciones de salud.

Reclute su personal de formas y fuentes diversas: Busque personal en grupos minoritarios, en lugares donde asistan personas con el perfil que usted busca.

Proporcione entrenamiento sobre la diversidad.

Recompense a las gerencias por promover la diversidad: Aliente a sus gerentes a contratar grupos minoritarios.

ACOSO SEXUAL

Establezca una directiva en contra del acoso: Desarrolle e implemente una política firme contra el acoso sexual. Explique los medios de reclamos, que serán investigados objetivamente y que los involucrados no tendrán ningún tipo de revancha y comuníqueselo a sus proveedores, clientes, y otros asociados de la directiva. 
Proporcione programas de entrenamiento: Capacite a sus supervisores para que creen un ambiente de trabajo positivo y libre de acosos.

Establezca un procedimiento para los reclamos: Proporcione vías correctas para la presentación y discusión de reclamos recibidos, como también un proceso justo para investigar estas acusaciones, que respete la privacidad, considera la posibilidad de crear una comisión.

Cree un ambiente propicio para la discusión del tema: Disponga de personal capacitado para asesorar y discutir sobre posibles casos de acoso y promueva discusiones y conferencias sobre el tema.

\section{ENTRENAMIENTO/CAPACITACIÓN/DESARROLLO PROFESIONAL}

Promueva el desarrollo de carreras: Para ayudar a su personal a reflexionar sobre sus funciones actuales e identificar objetivos a largo plazo y desarrollar su plan de carrera.

Cree un programa de Asesoramiento: Cree un mecanismo mediante el cual los colaboradores más antiguos puedan transmitir su experiencia profesional adquirida y aconsejar sobre la carrera.

Promueva y recompensa el desarrollo de talentos: Ofrezca incentivos que alienten a sus colaboradores a desarrollar sus talentos y educación.

Promueva y apoye el trabajo voluntario: Apoye a sus colaboradores a participar en proyectos de la comunidad.

DELEGACIÓN DE LA AUTORIDAD

Apoye la iniciativa inicial: Apoye a sus empleados a aportar nuevas ideas, tomar decisiones y ser creativos. 
Delegue autoridad a sus colaboradores para que alcance metas ambiciosas: Defina metas ambiciosas y dé a sus colaboradores flexibilidad para alcanzarlas.

Aplique la evaluación de desempeño por parte de múltiples supervisores: Conocida como evaluación de múltiples fuentes, pero sin la debida preparación de todos los involucrados, la medida puede ser mal interpretada y generar desconcierto entre sus colaboradores.

Provea información financiera de la compañía: Considera la posibilidad de compartir la memoria anual con sus colaboradores cada trimestre 0 anualmente.

RENUMERACIÓN E INCENTIVOS

Cree un programa de participación en resultados: Con este programa, el empleado tiene participación en las ganancias de la empresa de acuerdo con su desempeño.

Entregue acciones de la empresa como forma de incentivo: Es una forma de hacer participar en las ganancias e incentivar a sus colaboradores consiste en distribuir acciones de la empresa, basándose en metas individuales, de grupo, o de la propia empresa.

Estimule programas de retiro complementarios basados en el ahorro privado.

REDUCCIÓN DE ESTRUCTURA Y DESPIDOS

Evite despidos: Establezca un menú de opciones para determinar si hay costos que pueden ser recortados antes de de reducir personal. 
Comunique sus intenciones: Evite mantener secretos e informe a sus empleados

Identifique otras alternativas: Considere la posibilidad de reubicar o transferir a sus colaboradores.

Reduzca personal con dignidad: Trátelos con respeto y dignidad y proporcione los medios para ayudarlos a reubicarse en otro trabajo.

Dé explicaciones a los que mantuvo en sus puestos: Explique cuáles serán los cambios en su trabajo y cuales las nuevas oportunidades disponibles.

EQUILIBRIO ENTRE FAMILIA Y TRABAJO

Tenga en cuenta las necesidades de sus empleados.

Evite directivas y prácticas que interfieran entre familia y trabajo: Establezca metas empresariales que no interfieran en la vida familiar de sus colaboradores.

Sea flexible: Dentro de lo razonable ofrezca a sus empleados la oportunidad de ajustar sus agendas a sus necesidades personales.

Ofrezca días libres reenumerados para trámites personales.

Ofrezca variedad de opciones: Muchas de estas opciones comprobaron que pueden ayudar a reducir el estrés del empleado.

- División de tareas: Dos o más empleados dividen la responsabilidad de una única posición, recibiendo el mismo salario y beneficios

- Licencia personal: Licencia para atender asuntos personales.

- Trabajo a distancia: posibilidad para ejecutar tareas desde la casa. 
- Reducción voluntaria de la jornada de trabajo.

- Premio en licencia: Licencia concedida al empleado para atender asuntos particulares.

Motive a los gerentes a construir un ambiente de trabajo positivo: Para lograr una política de ambiente de trabajo flexible es necesario tener gerentes y supervisores que la motiven.

Ofrezca ayuda para la solución de problemas: Verifique qué alternativas tiene la empresa para ayudar a minimizar los problemas personales de sus colaboradores, de manera que ejecuten mejor sus tareas.

Apoye los cuidados prenatales.

Ayude a ubicar a los hijos de sus colaboradores en la escuela: Establezca como meta que todos los hijos de sus empleados asistan a la escuela y completen el Ciclo Básico Común. Comprometa a todos sus colaboradores y a sus familias con este objetivo.

Considere planes de salud para familiares a cargo.

Otorgue licencia reenumerada a sus colaboradores por necesidades familiares: Para los padres de recién nacidos.

Apoye la adopción.

Asóciese con otras empresas locales para ofrecer servicios.

Cree una clasificación de recursos existentes: Compile una lista de recursos disponibles en el área de su empresa, que puedan ser útiles a sus colaboradores para la solución de sus problemas familiares.

Establezca un centro de recursos para la familia. 


\section{Observaciones importantes}

Los temas tratados en "Reducción de estructura y despidos", "Equilibrio entre trabajo y familia" (tratados en este capitulo) y "Salud, Seguridad y Bienestar" (tratado en el siguiente capítulo), consúltelos con su asesor jurídico o abogado para asegurarse de que las políticas adoptadas estén de acuerdo con la legislación o estén acompañadas por una herramienta que asegure su legalidad.

\section{SALUD, SEGURIDAD Y BIENESTAR}

Promueva la salud y el bienestar: Cree una cultura empresarial que aprecie la salud personal, la seguridad y el bienestar.

Ofrezca planes de salud flexibles: Si su empresa ofrece planes de seguro y de salud para sus colaboradores, considera la posibilidad de disponer de una variedad de planes.

Promueva los controles de salud periódicos de salud. Recompense el estilo de vida saludable. Estimule la práctica deportiva en clubes y gimnasios. Elimine el cigarro de los ambientes de trabajo. Considere beneficios para el personal temporario: Considere la posibilidad de subsidiar total o parcialmente un plan de salud, así como otros beneficios, para sus colaboradores temporarios.. 


\section{Comunidad}
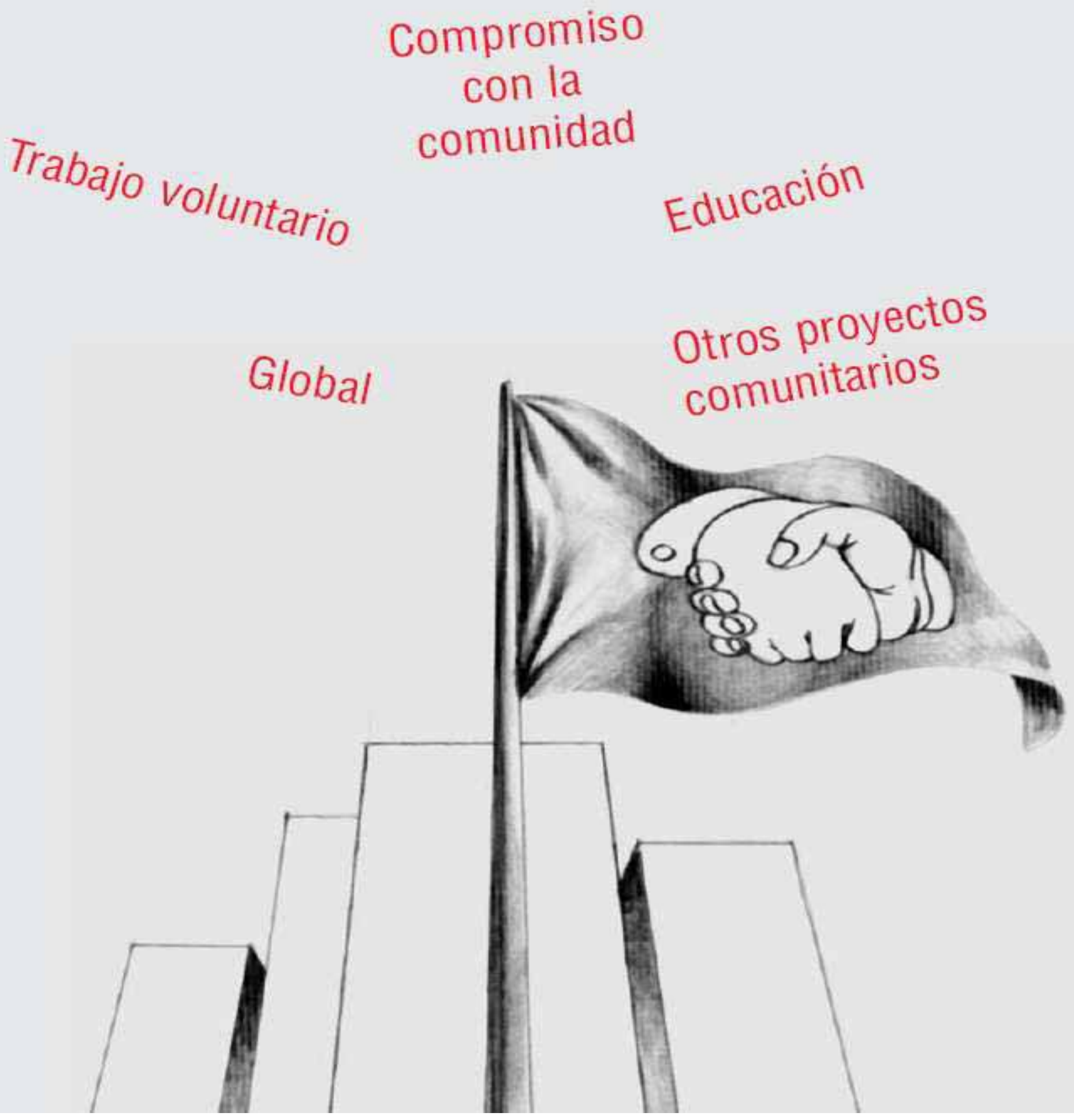


\section{COMUNIDAD}

\section{GLOBAL}

Haga del "compromiso con la comunidad" una prioridad de la administración: Aproveche todas las oportunidades para comunicar a sus empleados el apoyo a la comunidad y el compromiso con la misma es importante con la empresa.

Invierta en la comunidad: Utilice los servicios brindados por organizaciones comunitarias.

Considera la incorporación de personas provenientes de ambientes carenciados. Identifique e instale sus operaciones en comunidades carecientes..

\section{TRABAJO VOLUNTARIO}

Facilite información: Considere una lista de oportunidades de trabajos voluntarios.

Facilite tiempo para que sus colaboradores participen en programas de voluntariado.

Ofrezca apoyo financiero para estimular el trabajo voluntario: Considera la posibilidad de contribuir económicamente con organizaciones de cuya dirección formen parte sus colaboradores.

Recompense el trabajo voluntario de sus colaboradores. Adopte un proyecto específico. Autorice participación de gerentes y directivos y la aplicación de capacidades. Motive proveedores y clientes. Haga acuerdos con otras empresas: La alianza puede formarse basada en la implementación de un solo proyecto o en una serie de ellos. 
COMPROMISO CON LA COMUNIDAD

Haga donaciones de sus productos o servicios. Comprométase a hacer contribuciones. Aliente a sus empleados a contribuir.

Apoye eventos locales.

EDUCACIÓN

Ofrezca apoyo a escuelas locales. Haga donaciones de los equipos y mobiliarios usados o excedentes. Asóciese con una escuela: Provéela de servicios. Invite a los alumnos de la escuela a visitar su empresa. Proporcione padrinazgos. Cree un intercambio con la escuela: Intente crear una oportunidad de aprendizaje para el becario, practicante o alumno, así como para su empresa.

OTROS PROYECTOS COMUNITARIOS

Apoye el comercio local. Oriente al consumo en el comercio local, dando preferencias a minoristas. Facilite sus instalaciones: Considere la posibilidad de ceder espacios físicos de su empresa para encuentros de organizaciones y grupos sin fines de lucro.. 


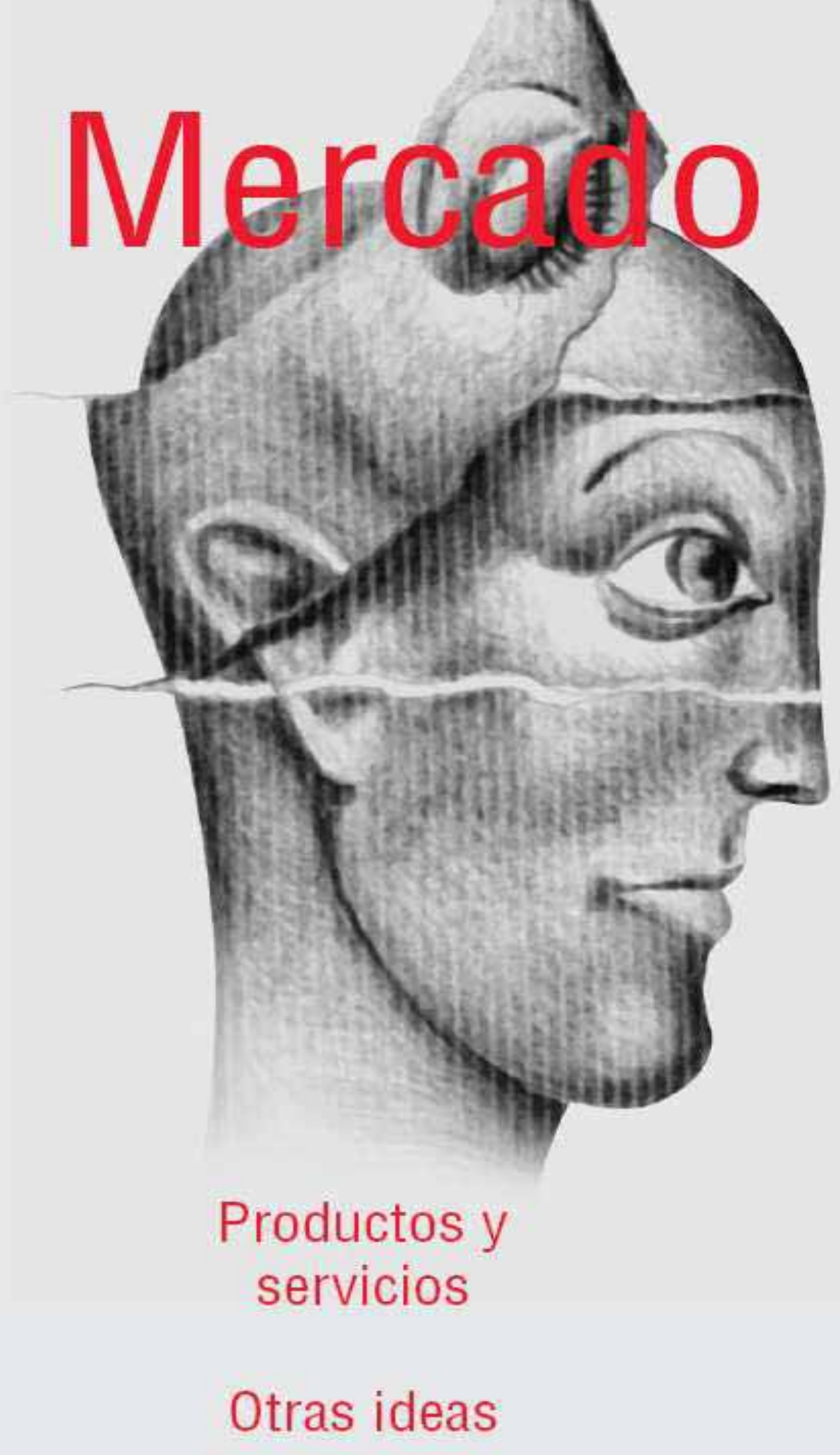

MERCADO

REDMARKA UIMA-Universidad de A Coruña - CIECID

Año 1, Número 2, (2009), pp. 111-182

http://www.redmarka.org/

ISSN 1852-2300 
PRODUCTOS Y SERVICIOS

Asegúrese de que todas las referencias comerciales hechas a los productos ylo servicios de la empresa sean específicas, correctas y justas: Vaya más allá de lo que especifica la ley específica, dando más información en sus productos sobre seguridad, desempeño y eficacia.

Promueva el uso de su producto con seguridad y responsabilidad: Asegúrese que su producto no perjudiquen la salud o el medio ambiente.

Prohíba el uso de técnicas comerciales noéticas. Facilite la mayor cantidad de información sobre sus productos. Respete la privacidad de sus clientes. Procure oportunidades comerciales alternativas: Cree nuevos productos y servicios que vayan al encuentro de las necesidades sociales.

Evite la publicidad tóxica: Establezca una directiva clara sobre el tipo de información y mensajes que se pueden transmitir.

Procure oportunidades de marketing que adhieran a causas nobles: Mercadeo hacia lo social y found raising.

OTRAS IDEAS

Haga inversiones de su empresa en instituciones socialmente responsables.

Utilice tarjetas de crédito, telefonía, etc. provistos por empresas con causas sociales. 


\section{Derechos Humanos}

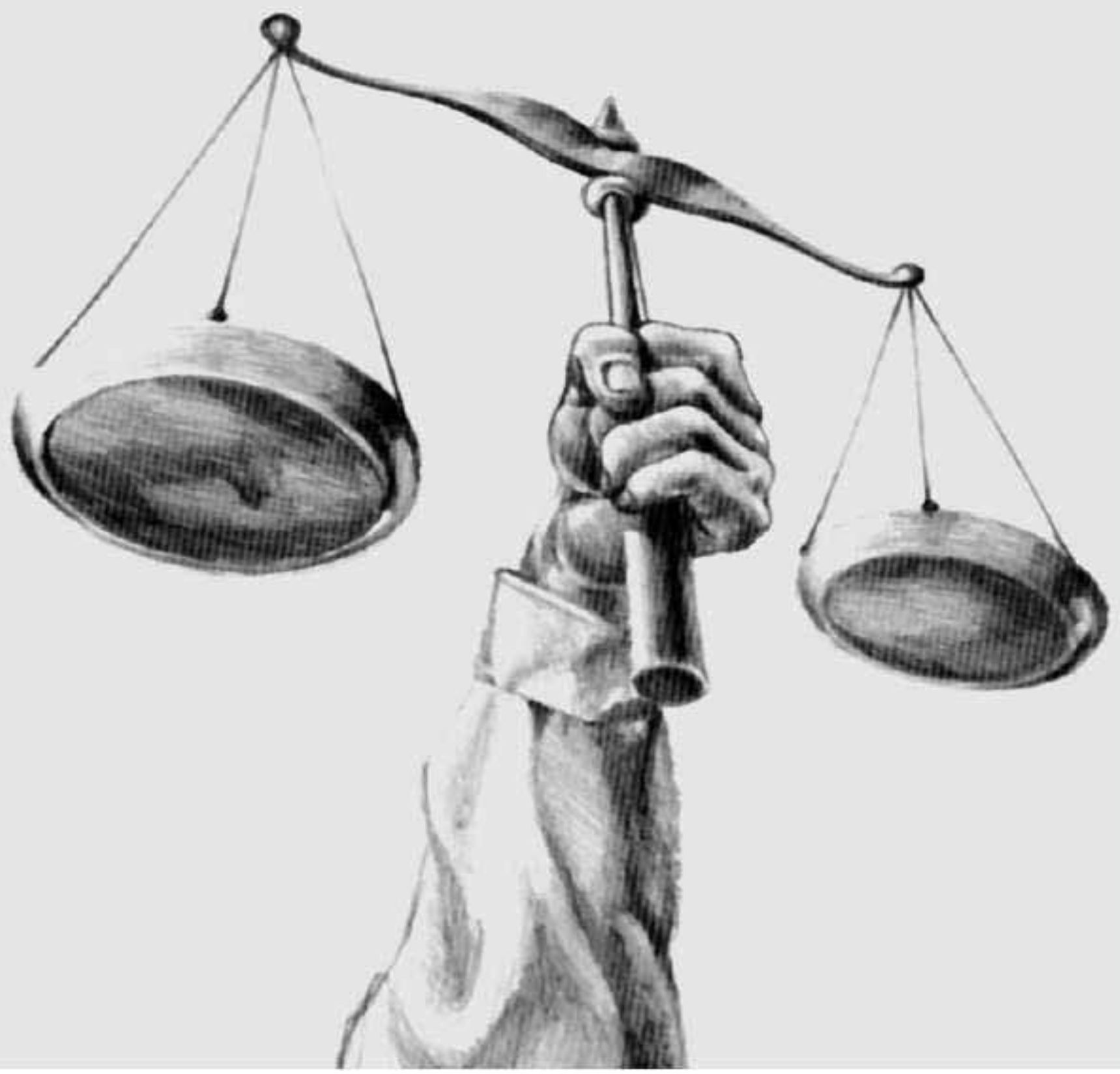

\section{DERECHOS HUMANOS}

REDMARKA UIMA-Universidad de A Coruña - CIECID

Año 1, Número 2, (2009), pp. 111-182

http://www.redmarka.org/

ISSN 1852-2300 
Considera los derechos humanos: Al elegir proveedores de productos y/o servicios, busque trabajar con asociados que compartan con su empresa la preocupación de dar un tratamiento justo a los trabajadores.

Sepa donde son manufacturados los productos de su empresa. Identifique aspectos relevantes sobre los derechos humanos. Adopte un código de conducta. Comunique sus expectativas a los proveedores. Solicite a los proveedores un compromiso formal. Utilice todas las oportunidades para monitorear el cumplimiento de las reglas establecidas. Trabaje en un clima de colaboración con proveedores para promover los cambios: Las grandes empresas saben que sus esfuerzos para promover cambios son más eficaces cuando no se imponen en forma autoritaria.

\section{PARTE IV:}

COSTA RICA: SITUACION ACTUAL

ASOCIACION EMPRESARIAL PARA EL DESARROLLO (AED)

RSE CONSULTORES: CECILIA MORA

\section{COSTA RICA; SITUACION ACTUAL}

"Los cambios están en camino".

En nuestro país es común el incumplimiento de la ley, por ejemplo, la morosidad de pagos, indicio que no todas las empresas que operan cumplen la legislación laboral vigente. Asimismo, no hay un discurso sobre el desarrollo de nuevas leyes ni de la mejor aplicación de legislación actual por parte de las empresas. Este vacío provoca en la ciudadanía una percepción simple al respecto de la RSE, visualizándola principalmente en hechos que afectan directamente la comunidad..

Desde el punto de vista políticoinstitucional no existe gran involucramiento en torno a la ejecución o fomento de prácticas de RSE. La buena imagen de las compañías no está condicionada por sus prácticas conforme a ley, es decir, no 
es necesario que una empresa este en regla para posicionarse bien en el mercado, vender o producir mercancías y generar utilidades.

Los desafíos que se presentan en Costa Rica se representan a las nuevas relaciones comerciales que se establecen a partir de los tratados de libre comercio (TLC). Las empresas públicas deberán adoptar modelos de competencia a los cuales no están acostumbrados. Las PyMES, las cuales son generadoras de empleo, de ingresos, dinamizadoras del desarrollo local y complemento de las grandes empresas. Estas deberán ajustarse, eventualmente, a los imperativos de la globalización. Será necesario un replanteamiento en su forma de hacer negocios, comenzando por abordar los problemas relacionados con el cumplimiento de normas.

Por lo tanto se hace imperioso reformar aspectos como la sensibilización y diseminación de la información, la inclusión de todos los sectores productivos es procesos de cambio para aumentar sus niveles de competitividad e incentivar la colaboración estratégica entre sectores productivos, sociales y políticos.

Costa Rica participa activamente en el proceso del ISO 26000 de Responsabilidad Social, el cual se encuentra desarrollando una guía que homologue los estándares internacionales de la temática.

Los momentos claves en términos ambientales en el país se identifican por varias iniciativas tales como A que sembras un árbol, Programa amigo con el cambio climático, La Paz con la naturaleza, Estrategia Nacional de Cambio Climático, entre otras.

Así mismo, Costa Rica está en rondas de negociación para establecer un acuerdo comercial con la Unión Europea. Lo que implica un reto para el país, en ser más competitivos y dejar ver a la RSE como una estrategia de mercadeo, ya que la Unión Europea tiene claramente desarrollado las prácticas de la responsabilidad social, lo aplican en sus tendencias comerciales y sus 
consumidores se preocupan mucho por los estándares de calidad pero sobre todo su impacto en el socio ambiente.

Los promotores de la RSE en Costa Rica, son todas aquellas organizaciones, asociaciones o instancias de gobierno o no gubernamentales tales como la Asociación empresarial para el desarrollo, consultores especialistas en el tema como Cecilia Mora, de la organización RSE consultores, y otros entes que intentan dar granitos de arena pero de mucha importancia en distintas áreas problemáticas del país, como la agencia de viajes Horizontes.

\section{ASOCIACION EMPRESARIAL PARA EL DESARROLLO}

\section{Quiénes somos}

AED es una organización empresarial sin fines de lucro que promueve la Responsabilidad Social Empresarial en

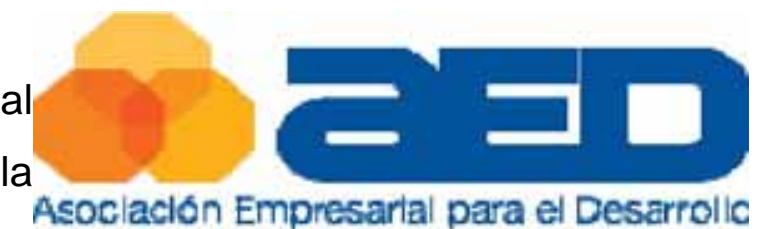
Costa Rica .

AED y sus empresas asociadas entienden la Responsabilidad Social Empresarial (RSE) como:

"El compromiso permanente de las empresas para aumentar su competitividad mientras contribuyen activamente al desarrollo sostenible de la sociedad costarricense mediante acciones concretas y medibles dirigidas a solucionar los problemas prioritarios del país".

\section{Misión}

Promover una nueva cultura de Responsabilidad Social Empresarial, que permita, por medio de participación directa, voluntariado, alianzas y fortalecimiento de instituciones sin fines de lucro, fomentar el desarrollo humano sostenible del país. 


\section{Principios}

- Los individuos son los responsables del desarrollo de sus comunidades

-El desarrollo de las comunidades no se sustenta sin el cuidado del medio ambiente.

- Las empresas y su intervención eficaz son factores claves en el desarrollo integral y sostenible de las comunidades.

-El aprendizaje continuo es la base del mejoramiento de nuestro desempeño.

-Integridad y transparencia son los pilares de nuestra credibilidad como organización.

\section{Vicepresidente}

Alberto Borbón Hulera Costarricense

\section{Secretario}

Alejandra Cobb Procter \& Gamble

\section{Prosecretaria}

Yolanda Fernández Wal Mart

\section{Tesorera}

Fausto Bejarano - Plycem Construsistemas

\section{Vocal}

Paul Bornemisza - Sardimar

\section{Valores}




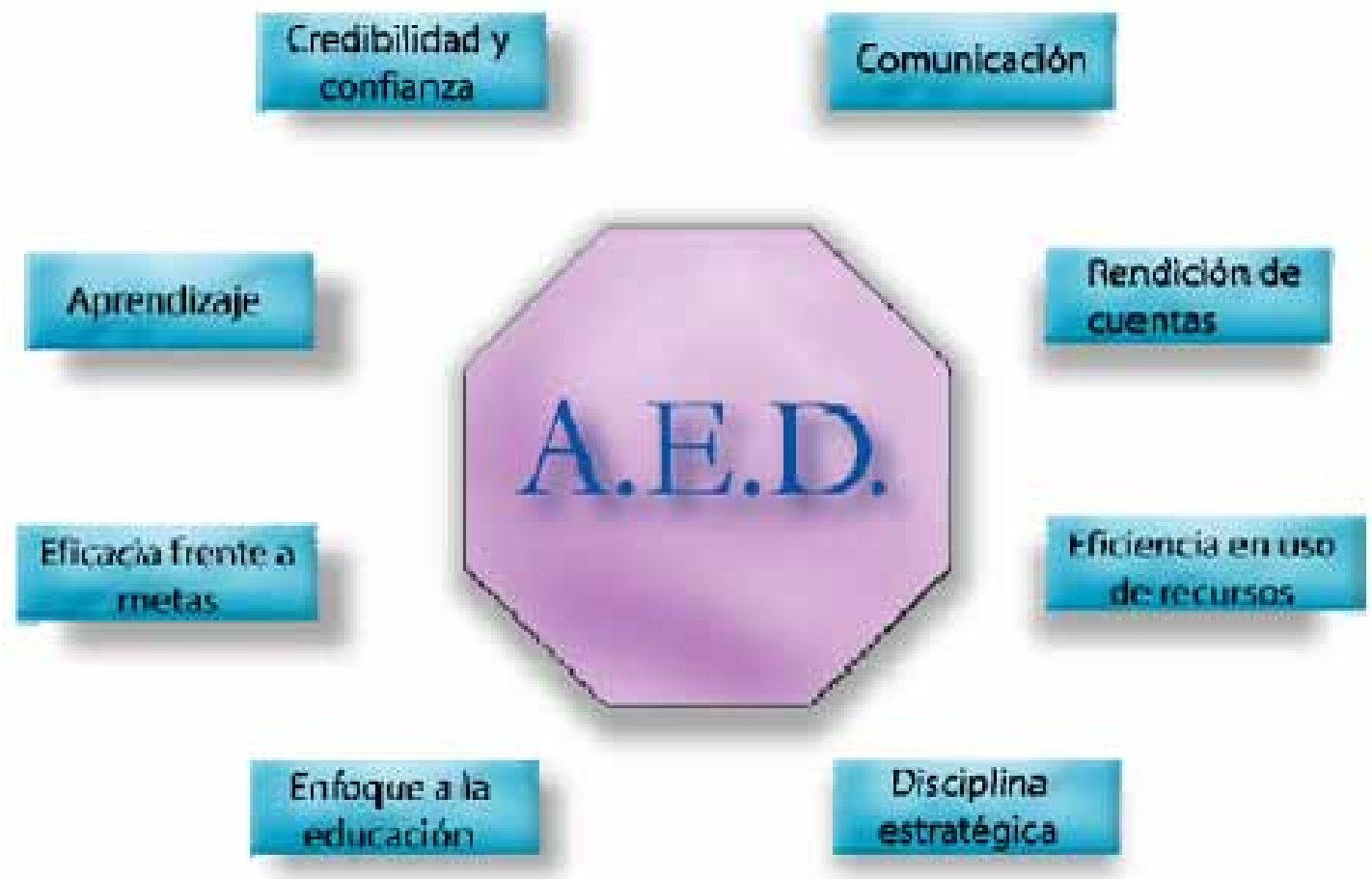

\section{Vocal}

Alfredo Montealegre - Génesis Desarrolladores

\section{Vocal}

Franco Pacheco Musmanni

\section{Vocal}

Roberto Tovar - Corrugados Belén

\section{Junta Directiva}

\section{Vocal}

Maximiliano Alvarado - Banco Nacional de Costa Rica

Luis Javier Castro Mesoamérica

\section{Presidente}

Roxana Víquez - BAC San José 
Alexandra Kissling Corporación Rostipollos

\author{
Vocal \\ Emilia Amado PriceWaterHouseCoopers \\ Fiscal
}

\title{
Alianzas internacionales
}

AED está asociada a tres reconocidos organismos internacionales:

\section{WBCSD}

Es una coalición de 180 compañías internacionales unidas para promover al desarrollo sostenible con desarrollo económico, equilibrio ecológico y progreso social. Representa a más de 30 países y 20 sectores industriales de los más importantes del mundo (12\% del PIB mundial).

Para visitar el sitio Web de WBCSD, el enlace es: http://www.wbcsd.org

\section{Forum Empresa}

Es una alianza hemisférica de organizaciones empresariales de 20 países que promueven la Responsabilidad Social Empresarial (RSE) en las Américas, reúne a 3.500 empresas. Para visitar el sitio Web de Forum Empresa, el enlace es http://www.empresa.org.

\section{United Way}

Es una red global de organizaciones sin fines de lucro que funcionan en 45 países con el propósito de unir esfuerzos y recaudar recursos para contribuir a solucionar los problemas de las diferentes comunidades.

El sitio Web de United Way, es el enlace: http://www.uwint.org

\section{Empresas asociadas por categoría:}


Empresas Walter Kissling

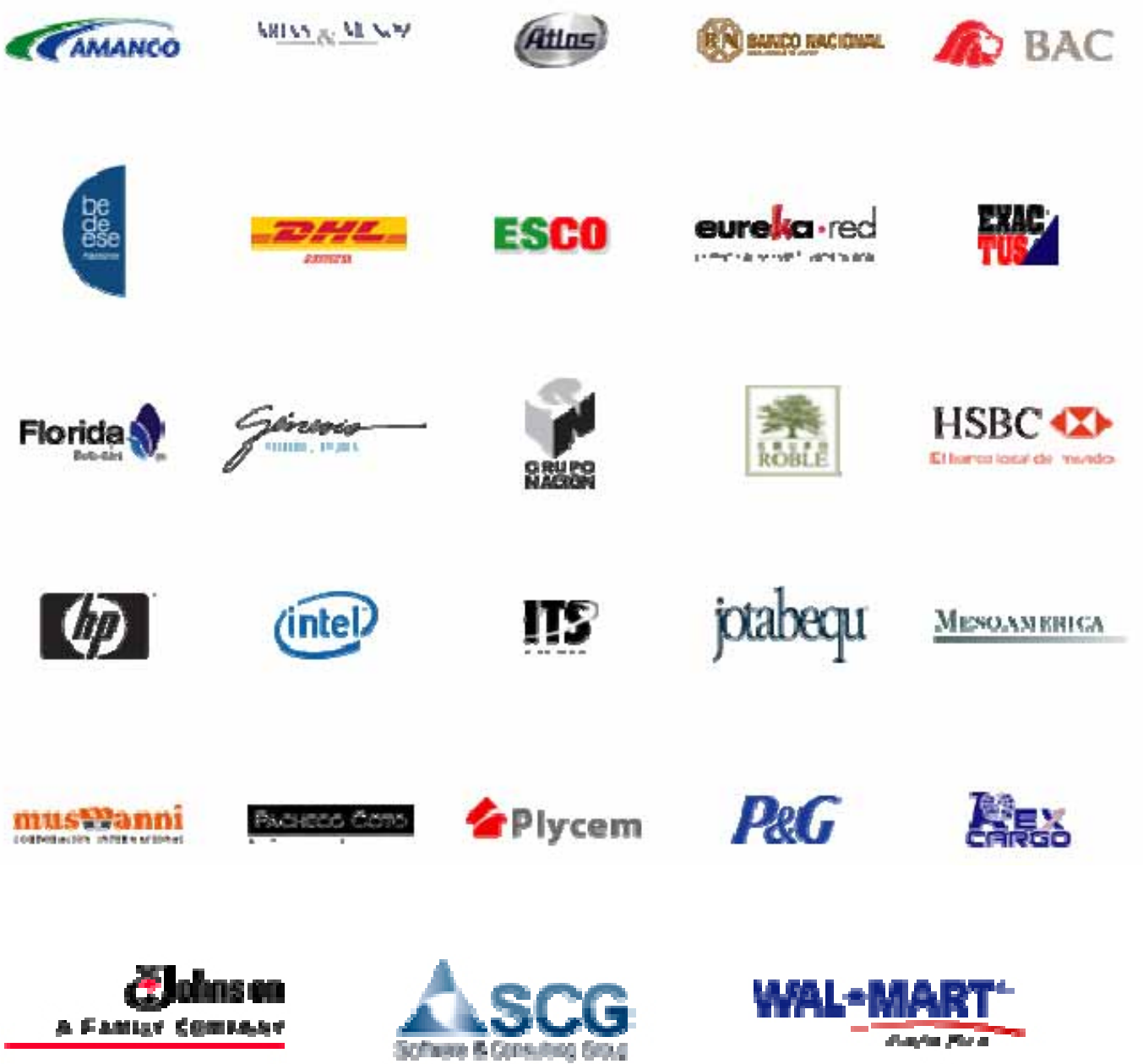

Sardimar

Empresas Categoría Honor

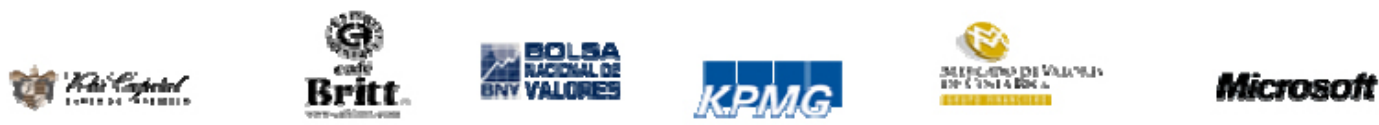

\section{Empresas categoría solidario}

BLP Abogados 
Ernst \& Young

Grupo Marta

Arcelor Mittal

Price Waterhouse Cooper

Scotiabank

Interamericana de Comunicación

\section{Empresas Categoría Amigo}

Aura Interactiva

Bridgestone Firestone

Centro Cultural Costarricense Norteamericano

Grupo Garnier

Holtermann \& Compañía

Hulera Costarricense

Mundanzas Mundiales

Próxima Comunicación

Real Intercontinental

Subway

TIPOS DE CATEGORIA

\section{Categoría Walter Kissling}

Las empresas Walter Kissling cuentan con los siguientes servicios:

Productos Gestión Empresarial RSE:

- Documento con el Marco conceptual e indicadores del Modelo de RSE para Costa Rica.

- Acompañamiento y asesoría básica de 12 horas consultor para el proceso de auto- evaluación. 
- Participación en el proceso de benchmarking de AED y reporte de resultados.

- Consultas sobre temáticas de gestión empresarial basada en RSE (vía correo electrónico).

- Documentos impresos con cinco Módulos Didácticos de casos de buenas prácticas en RSE.

Servicios Formación RSE:

- Una charla de sensibilización para mandos altos y medios sobre el Modelo de RSE para Costa Rica.

- Participación con dos cupos en el foro temático anual que organiza AED sobre temas de RSE de actualidad.

- Participación con dos cupos en el Foro de intercambio de mejores prácticas de RSE.

- Participación con un cupo en la Jornada Anual de RSE.

- Descuento del 15\% en curso intensivo de formación en RSE.

Información sobre RSE:

- Intercambio de información innovadora sobre RSE mediante las alianzas que tiene AED con: Consejo Empresarial para el Desarrollo Sostenible (WBCSD), Forum Empresa y United Way Internacional.

Inversión Social Responsable en Comunidad:

- Asesoría para el trabajo en comunidad mediante la participación en el Programa Binomio.

- Posibilidad de realizar en la empresa el Programa "Un Poquitico de Mi".

Visibilidad: 
- Posibilidad de colocar en la Web de AED un caso de Negocios de la empresa.

- Mención destacada en una publicación anual de media página en el Periódico La Nación.

- Posibilidad de incorporar el logo de AED en las publicaciones de RSE de la Empresa (según los lineamientos del uso de imagen de AED.

- Banner con logo y link a la empresa en el Home Page del sitio WEB de AED.

- Mención destacada y logo en la Memoria Anual de AED.

- Mención de la empresa en las oportunidades de publicity con las que cuente AED.

Valor Agregado

- Pertenencia a una organización socialmente responsable

- Oportunidad de integrarse activamente a un "Proyecto país" que promueve el desarrollo humano sostenible.

- La empresa accede a un esquema de inversión social responsable, maximiza los recursos al tiempo que genera un mayor impacto positivo en la sociedad.

- Garantía de un manejo transparente y eficaz de los recursos.

- Reconocimiento como empresa que contribuye con el desarrollo nacional.

\section{Categoría Honor}

Las empresas Honor cuentan con los siguientes servicios:

Productos Gestión Empresarial RSE:

- Documento con el Marco conceptual e indicadores del Modelo de RSE para Costa Rica. 
- Acompañamiento y asesoría básica de 12 horas consultor para el proceso de auto- evaluación.

- Participación en el proceso de benchmarking de AED y reporte de resultados.

- Consultas sobre temáticas de gestión empresarial basada en RSE (vía correo electrónico).

- Documentos impresos con cinco Módulos Didácticos de casos de buenas prácticas en RSE.

Servicios Formación RSE:

- Una charla de sensibilización para mandos altos y medios sobre el Modelo de RSE para Costa Rica.

- Participación con un cupo en el foro temático anual que organiza AED sobre temas de RSE de actualidad.

- Participación con un cupo en el Foro de intercambio de mejores prácticas de RSE.

- Participación con un cupo en la Jornada Anual de RSE.

- Descuento del 5\% en curso intensivo de formación en RSE.

Información sobre RSE

- Intercambio de información innovadora sobre RSE mediante las alianzas que tiene AED con: Consejo Empresarial para el Desarrollo Sostenible (WBCSD), Forum Empresa y United Way Internacional.

Inversión Social Responsable en Comunidad:

- Asesoría para el trabajo en comunidad mediante la participación en el Programa Binomio.

- Posibilidad de realizar en la empresa el Programa "Un Poquitico de Mi".

Visibilidad: 
- Mención de la empresa en una publicación anual de media página en el Periódico La Nación.

- Posibilidad de incorporar el logo de AED en las publicaciones de RSE de la Empresa (según los lineamientos del uso de imagen de AED).

- Mención de la empresa en la WEB de AED.

- Mención de la empresa en las oportunidades de publicity con las que cuente AED.

Valor Agregado:

- Pertenencia a una organización socialmente responsable

- Oportunidad de integrarse activamente a un "Proyecto país" que promueve el

- desarrollo humano sostenible.

- La empresa accede a un esquema de inversión social responsable, maximiza los recursos al tiempo que genera un mayor impacto positivo en la sociedad.

- Garantía de un manejo transparente y eficaz de los recursos.

- Reconocimiento como empresa que contribuye con el desarrollo nacional.

\section{Categoría solidario}

Las empresas Solidario cuentan con los siguientes servicios:

Productos Gestión Empresarial RSE:

- Documento con el Marco conceptual e indicadores del Modelo de RSE para Costa Rica.

- Consultas sobre temáticas de gestión empresarial basada en RSE (vía correo electrónico).

Servicios Formación RSE: 
- Participación con un cupo en el foro temático anual que organiza AED sobre temas de RSE de actualidad.

Información sobre RSE:

- Intercambio de información innovadora sobre RSE mediante las alianzas que tiene AED con: Consejo Empresarial para el Desarrollo Sostenible (WBCSD), Forum Empresa y United Way Internacional.

Inversión Social Responsable:

- Posibilidad de realizar en la empresa el Programa "Un Poquitico de Mi"

Visibilidad:

- Mención de la empresa en una publicación anual de media página en el Periódico La Nación.

- Posibilidad de incorporar el logo de AED en las publicaciones de RSE de la Empresa (según los lineamientos del uso de imagen de AED).

- Mención de la empresa en la WEB de AED.

- Mención de la empresa en la Memoria Anual de AED.

Valor Agregado:

- Pertenencia a una organización socialmente responsable

- Oportunidad de integrarse activamente a un "Proyecto país" que promueve el desarrollo humano sostenible.

- La empresa accede a un esquema de inversión social responsable, maximiza los recursos al tiempo que genera un mayor impacto positivo en la sociedad.

- Garantía de un manejo transparente y eficaz de los recursos. 
- Reconocimiento como empresa que contribuye con el desarrollo nacional.

\section{Categoría Amigo:}

Las empresas Amigo cuentan con los siguientes servicios:

Productos Gestión Empresarial RSE:

- Documento con el Marco conceptual e indicadores del Modelo de RSE para Costa Rica.

- Posibilidad de realizar en la empresa el Programa "Un Poquitico de Mi".

Inversión Social Responsable:

- Posibilidad de realizar en la empresa el Programa "Un Poquitico de Mi"

Visibilidad:

- Mención de la empresa en la WEB de AED.

- Mención de la empresa en la Memoria Anual de AED.

Valor Agregado:

- Pertenencia a una organización socialmente responsable.

- Oportunidad de integrarse activamente a un "Proyecto país" que promueve el desarrollo humano sostenible.

- La empresa accede a un esquema de inversión social responsable, maximiza los recursos al tiempo que genera un mayor impacto positivo en la sociedad.

- Garantía de un manejo transparente y eficaz de los recursos. 
- Reconocimiento como empresa que contribuye con el desarrollo nacional.

MÁS A FONDO

\section{Inversión social}

AED sirve como canal del sector privado para que las empresas puedan realizar una inversión socialmente responsable que les permita impactar positivamente en uno de los problemas prioritarios del país: la pobreza.

\section{Relación pobreza- educación}

AED cree posible reducir la pobreza en el país mediante el remozamiento de la educación de los sectores en desventaja económica.

\section{Propuesta de AED}

AED promueve la educación como base de un modelo de desarrollo humano sostenible que reduce la pobreza, promueve la movilidad social, la estabilidad democrática y mejora la calidad de vida.

Para ello provee una plataforma de inversión socialmente responsable mediante sus Iniciativas Estratégicas en Educación que promueven una alianza público privada para el desarrollo humano sostenible.

\section{¿Qué son las Iniciativas Estratégicas en Educación?}

Las Iniciativas Estratégicas en Educación representan una propuesta para abordar algunos de los principales desafíos de la educación costarricense con el aporte y apoyo de empresas, empresarios, trabajadores, organizaciones sociales y comunidades educativas. 
Contempla específicamente seis Iniciativas: Tecnología, Pensamiento Crítico, Prevención de la Deserción y Exclusión, Prevención de la Violencia, Empleabilidad, Arte Creatividad e Innovación. Además incluye el componente de Gerencia y Estrategia para promover la transferencia de competencias empresariales a las comunidades educativas, para fortalecer su capacidad de auto gestión y emprendimiento.

Para cada uno de estos retos AED desarrolla una serie de proyectos que son ejecutados por diversas Organizaciones Sociales expertas en el abordaje en esos temas.

\section{Gerencia y estrategia}

Esta área incluye el programa Binomio que consisten en un voluntariado profesional estratégico para crear sinergias entre los gerentes de las empresas y los principales actores de las comunidades educativas a través de un Comité de Responsabilidad Comunitaria, con el objetivo de desarrollar y fortalecer los modelos gerenciales dentro de los centros educativos.

\section{Programa Binomio}

\section{Misión}

Contribuir con el desarrollo sostenible de Costa Rica, mediante un voluntariado estratégico y empoderamiento de líderes en comunidades del país a través de sus instituciones educativas.

\section{Visión al 2010}

Crear un modelo de emprendimiento social y empoderamiento comunitario replicable a escala nacional basado en el desarrollo y transferencia de las 
mejores prácticas en gerencia y estrategia, mediante la interacción de voluntarios empresariales y líderes de comunidades educativas.

\section{Comités de Responsabilidad Comunitaria}

\section{Misión:}

Contribuir con el Desarrollo Sostenible de Costa Rica, a través de la promoción de la responsabilidad social comunitaria.

\section{Visión al 2010}

Ser el programa que genere el cambio de cultura de participación ciudadana en las comunidades escolares.

\section{Un poquítico de mí}

\section{¿Qué es un Poquitico de Mí?}

Es un programa de deducción voluntaria por nómina mediante el cual los trabajadores de las empresas asociadas a AED invierten un aporte individual para el modelo de Desarrollo Social en las comunidades escolares seleccionadas.

\section{¿Cuáles son los beneficios para los Afiliados?}

- Inversión y Maximización de los recursos.

- Confianza y seguridad en el manejo de los recursos.

- Información constante sobre en cuáles proyectos se realiza la inversión de su aporte. En este sentido cada afiliado recibe un boletín informativo trimestral, correos y mensajes periódicos. 
- Carné de afiliado que le permite participar en rifas y recibir diversos descuentos.

En este momento están afiliados a Un Poquitico de Mí 4200 trabajadores del área operativa, mandos medios, administrativos y gerenciales.

El trabajador puede ingresar con la cantidad que desee y que se adapte a sus posibilidades.

\section{Modelo AED de Responsabilidad Social para empresas Costarricenses} CONTEXTO EN EL QUE OPERAN LAS EMPRESAS COSTARRICENSES

Principales desafíos costarricenses que frenan el desarrollo del sector privado local.

Como fase previa al diseño del modelo AED de Responsabilidad Social para empresas Costarricenses, se realizó una evaluación de los mayores desafíos que enfrenta el país y que de alguna forma frenan el desarrollo del sector privado local.

Entre las fuentes que se consultaran para dicho análisis se pueden mencionar el Informe Estado de la Nación del programa de las Naciones Unidas para el desarrollo (PNUD), el reporte de Competitividad Global del Foro Económico Mundial, Índice de Percepción de la corrupción de Transparencia internacional y el Banco Mundial. 
Principales problemas que afectan la competitividad de Costa Rica:

\section{Problemas}

\begin{tabular}{|l|}
\hline Educación \\
\hline Pobreza y bajos ingresos \\
\hline Corrupción \\
\hline
\end{tabular}

Déficit del sector público

Inversión en infraestructura crítica

Necesidades de mayor inversión

Desempleo

Desarrollo de ciencia y tecnología

Protección ambiental

Trabajo infantil

Salud

Malnutrición

\section{Ejemplos de freno al desarrollo}

\begin{tabular}{l}
\hline Calidad de educación primaria y falta de educación técnica. \\
\hline Demanda interna débil. Capacidad de ahorro baja. \\
\hline Aleja inversionistas. Incrementa el riesgo pais. \\
\hline $\begin{array}{l}\text { Carencia de recursos para inversión en educación, salud, } \\
\text { infraestructura y seguridad. }\end{array}$ \\
\hline Insuficiencia de carreteras, puertos y servicios de comunicaciones. \\
\hline $\begin{array}{l}\text { Empresas con capacidad de crecimiento limitada por falta de } \\
\text { capital. }\end{array}$ \\
\hline Contracción de la demanda interna. Incremento de delincuencia. \\
\hline $\begin{array}{l}\text { Baja innovación. Economías basadas en producción de } \\
\text { "commodities." }\end{array}$ \\
\hline $\begin{array}{l}\text { Sistema regulatorio cébil. Falta de consistencia en aplicación. } \\
\text { Insumos contaminados. }\end{array}$ \\
\hline $\begin{array}{l}\text { Tiempo insuficiente para la educación. Recursos humanos poco } \\
\text { capacitados. Riesgo en mercados internacionales (e.g.. boicots). }\end{array}$ \\
\hline Sistema nacional débil, y empeorándose. \\
\hline Imposibilita el pleno desarrollo de capacidades mentales y físicas. \\
\hline
\end{tabular}

La RSE en Costa Rica: Encuesta de PriceWater House Coopers:

La investigación abarco una muestra de 12 empresas, de las cuales el 19\% reporto tener prácticas o políticas de RSE. El principio más importante sobre el que se basan las acciones de RSE en la mayoría de empresas es al igual que a nivel mundial, "los valores, ética y código de conducta", con un 93\% que lo considera muy influyente. La siguiente figura 1 , se muestra la forma en que las compañías costarricenses realizan su reporte público, precisando asimismo, que el $33 \%$ de de las empresas no efectúa ningún tipo de reporte o informe sobre su desempeño social y ambiental.

Figura 1. Formas en que las empresas costarricense realizan su reporte público de RSE versus el promedio de las compañías del resto del mundo. 


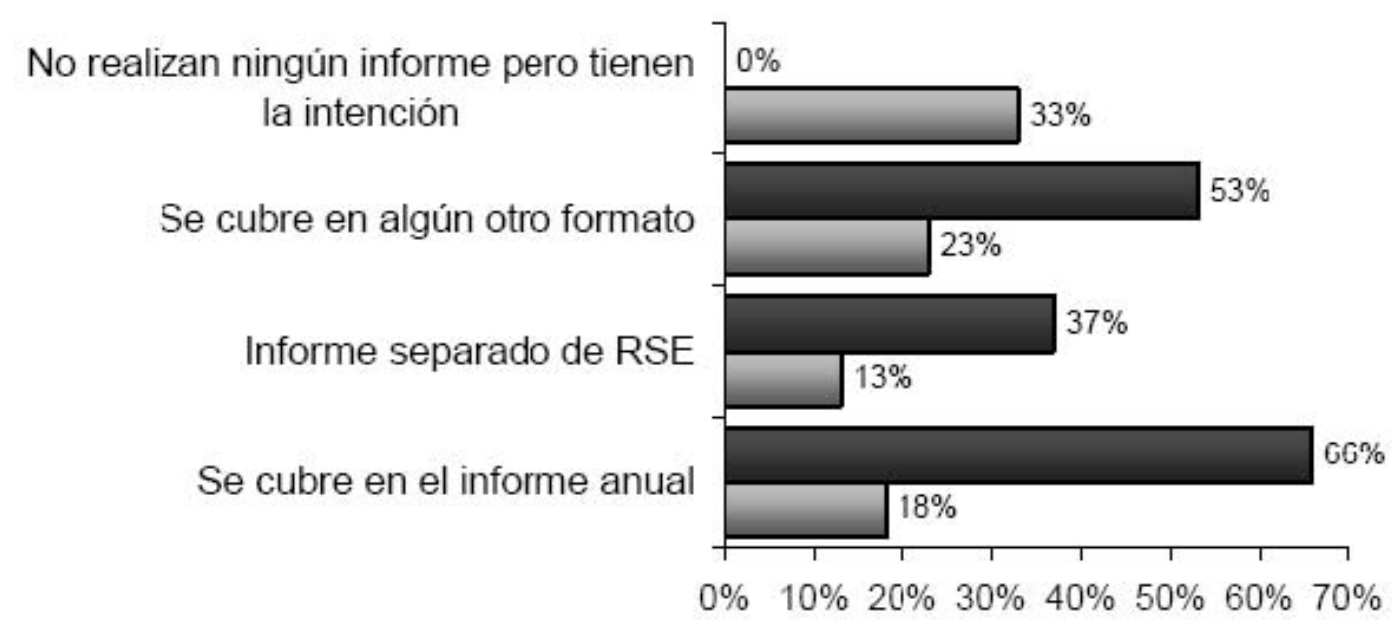

$\square$ Costa Rica $\square$ Mundial

RSE: UNA PROPUESTA PARA EL SECTOR PRIVADO COSTARRICENSE

\section{Modelo Conceptual}

El propósito de este modelo es establecer las áreas que deben ser considerar las empresas costarricenses que deseen cumplir con su responsabilidad social. Para acompañar este modelo conceptual, se desarrollo un manual de indicadores con el fin de proveer a las empresas un instrumento de autodiagnóstico que les permita auto-evaluar su desempeño en las distintas áreas.

El propósito de este modelo es establecer las áreas que deben ser considerar las empresas costarricenses que deseen cumplir con su responsabilidad social. Para acompañar este modelo conceptual, se desarrollo un manual de indicadores con el fin de proveer a las empresas un instrumento de autodiagnóstico que les permita auto-evaluar su desempeño en las distintas áreas.

Figura 2. Hexágono de la responsabilidad social para empresas costarricenses. 


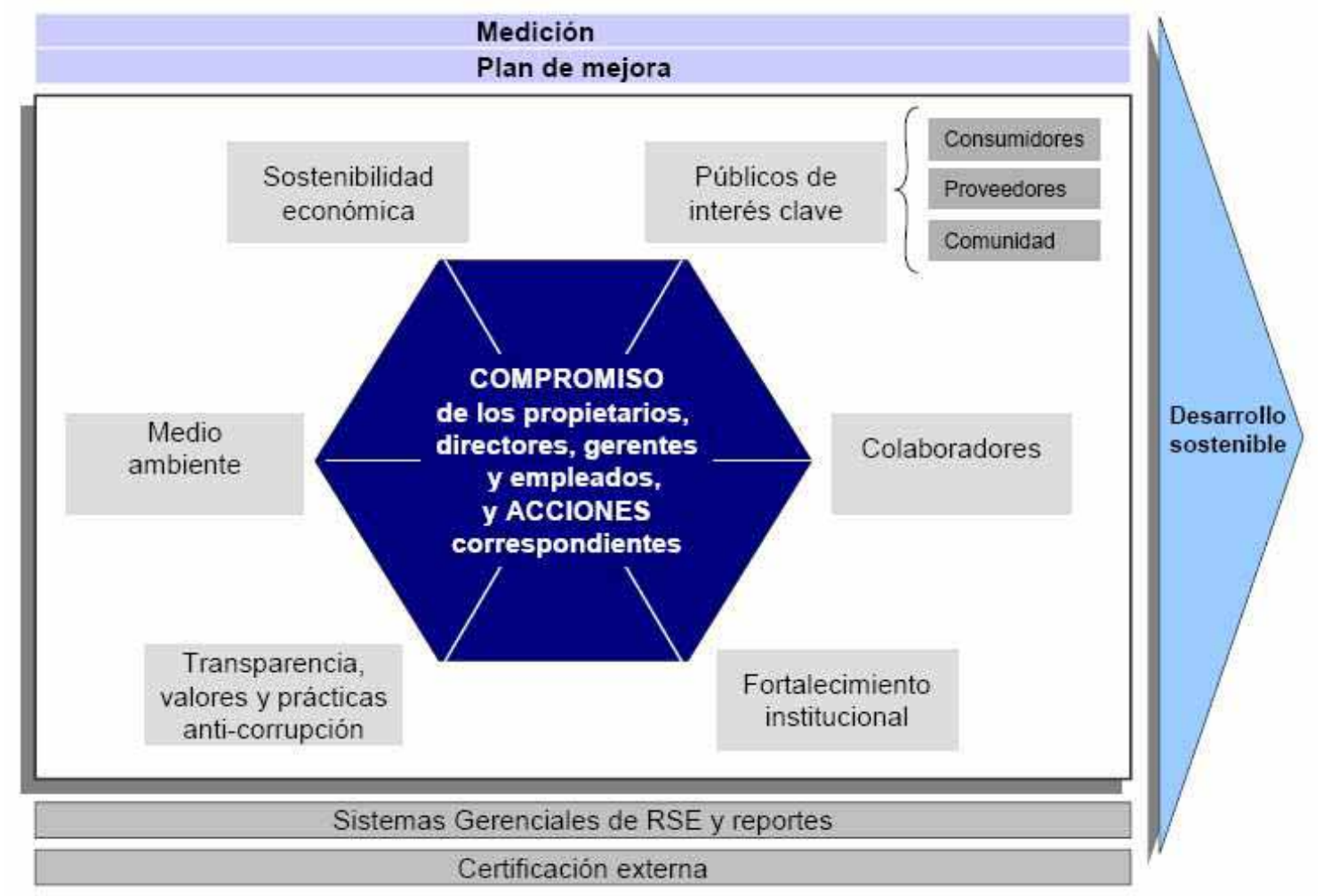

El núcleo de una conducta empresarial socialmente responsable lo contribuye el compromiso de los propietarios, directores, gerentes y empleados de las empresas. Los accionistas y altos directivos de las compañías son los primeros llamados a impulsar iniciativas de RSE en sus organizaciones, y paralelamente desarrollar la cultura de responsabilidad social entre sus colaboradores.

La medición del desempeño es un componente esencial para la toma de decisiones y por lo tanto tiene que estar presente en cada una de las categorías propuestas.

La utilización sistemas gerenciales que incluyan planes de acción documentados es el siguiente paso para traducir los compromisos originales para acciones concretas y medibles.

El esfuerzo en conjunto de las empresas, traducido en acciones concretas en estas seis categorías, así como los factores comunes a estas (medición, plan de mejora, sistemas gerenciales, reportes y certificaciones externas), asegura una contribución efectiva del sector privado al desarrollo sostenible de la REDMARKA UIMA-Universidad de A Coruña - CIECID

Año 1, Número 2, (2009), pp. 111-182 
sociedad costarricense, y en consecuencia al desarrollo de su propia competitividad.

Transparencia, valores y prácticas anti- corrupción

Los valores y principios de una compañía más que simple enunciados deben ser códigos de conducta vivos, que normen el proceder diarios de los accionistas y colaboradores a todo nivel. Para alcanzar este objetivo es necesario contar con mecanismos de comunicación y canales de discusión accesibles y efectivos.

\section{Colaboradores}

El éxito de toda organización depende de la calidad y compromiso de su recurso humano, y de las condiciones en que este desempeña sus funciones.

Públicos interés claves:

- Consumidores: Los clientes son la razón de ser de las empresas.

- Proveedores: Contribuir al desarrollo de los proveedores, en especial de las micro y pequeñas empresas.

- Comunidad: La responsabilidad de la compañía con la comunidad se traduce en el respeto a las costumbres y normas locales, así como su contribución al desarrollo. Medio ambiente: La responsabilidad de la empresa con el cuidado del medio ambiente y la conservación del planeta, comienza por el compromiso de la organización con la causa ambiental.

- Fortalecimiento Institucional: Bajo la premisa de que las empresas y el sector público son carentes de recursos, la contribución del sector privado para mejorar la situación se hace imperativa.

- Sostenibilidad Económica: Las empresas deben estar orientadas a generar valor para los accionistas, enfocándose en la obtención de resultados sólidos, que paralelamente permitan mejorar la calidad de 
vida de sus empleados y comunidades, proteger el medio ambiente y contribuyendo así a la competitividad del país. La responsabilidad de las empresas pasa también por considerar los aspectos de planteamiento estratégico, seguimiento al desempeño económico y financiero, gerencia de crisis y riesgo, desarrollo, transferencia y difusión de ciencia y tecnología, y política de reinversión de utilidades.

Mapa de categorías y subᄀcategorías

Para que el modelo de RSE logre alcanzar credibilidad nacional e internacional se incluyeron las subᄀcategorías de responsabilidad contempladas dentro de cada una de las categorías del Hexágono de RSE, ver Figura 3, las cuales son consistentes con las iniciativas de RSE reconocidas a nivel internacional, y las cuales a su vez han sido ajustadas a la realidad costarricense con base a un proceso de consulta y validación que convoco la participación de las distintas partes interesadas.

Las herramientas que utiliza AED para mantener su modelo de RSE competitivo:

Figura 4. Categorías y Sub Categorías

CATEGORIA

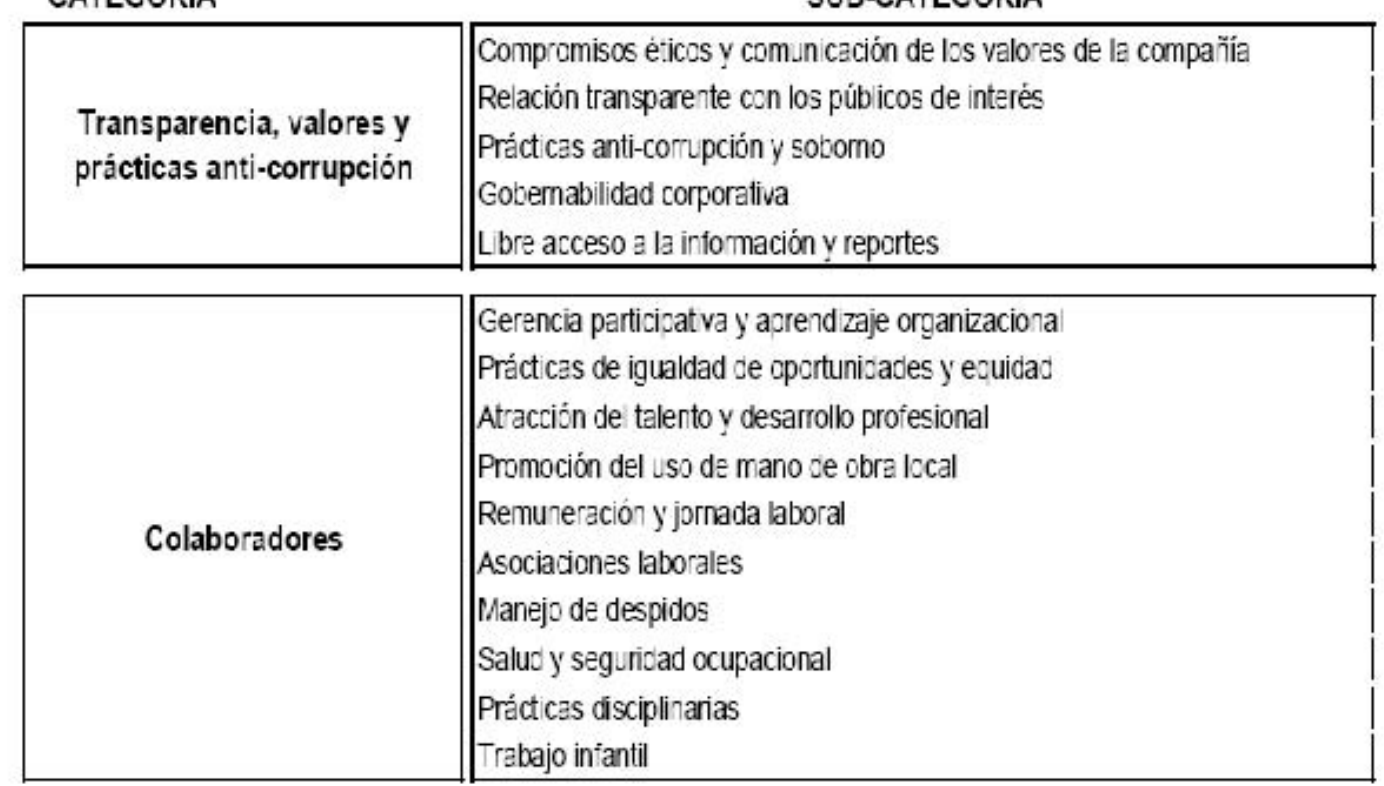




\begin{tabular}{|c|c|c|}
\hline \multirow{3}{*}{$\begin{array}{l}\text { Públicos de } \\
\text { interés clave }\end{array}$} & Consumidores & $\begin{array}{l}\text { Prácticas de mercadeo y publicidad } \\
\text { Seguridad y calidad de los productos y servicios } \\
\text { Atención al cliente y garantías }\end{array}$ \\
\hline & Proveedores & $\begin{array}{l}\text { Criterios de selección de proveedores } \\
\text { Apoyo al desarrollo sostenible de sus proveedores }\end{array}$ \\
\hline & Comunidad & $\begin{array}{l}\text { Inversiones, donaciones y participación en proyectos sociales } \\
\text { Implementación de proyectos socales } \\
\text { Trabajo voluntario promovido por la empresa } \\
\text { Patrimonio socio-cultural }\end{array}$ \\
\hline \multicolumn{2}{|c|}{ Medio ambiente } & $\begin{array}{l}\text { Compromiso con el mecio ambiente } \\
\text { Educación ambiental } \\
\text { Impacto ambiental de la activicad productiva } \\
\text { Impacto ambiental del producto terminado } \\
\text { Desarrollo de tecnologías ambien:almente amigables }\end{array}$ \\
\hline \multicolumn{2}{|c|}{ Fortalecimiento institucional } & $\begin{array}{l}\text { Tributación y respeto por la soberanía nacional } \\
\text { Participación en proyectos sociales con el gobierno } \\
\text { Transparencia en el rol político de la organización } \\
\end{array}$ \\
\hline \multicolumn{2}{|c|}{ Sostenibilidad económica } & $\begin{array}{l}\text { Planeamiento estratégico } \\
\text { Desempeño económico y finarciero } \\
\text { Desarrollo, transferencia y difusión de ciencia y tecnologia } \\
\text { Gerencia de crisis y riesgo y vulnerabilidad frente a desastres y siniestros } \\
\text { Política de reinversión de utilidades }\end{array}$ \\
\hline
\end{tabular}

La herramientas que utiliza AED para evaluar su modelo RSE y su desarrollo, se observan en la figura 4:

Figura 4. Herramientas del modelo de RSE para empresas costarricenses. 


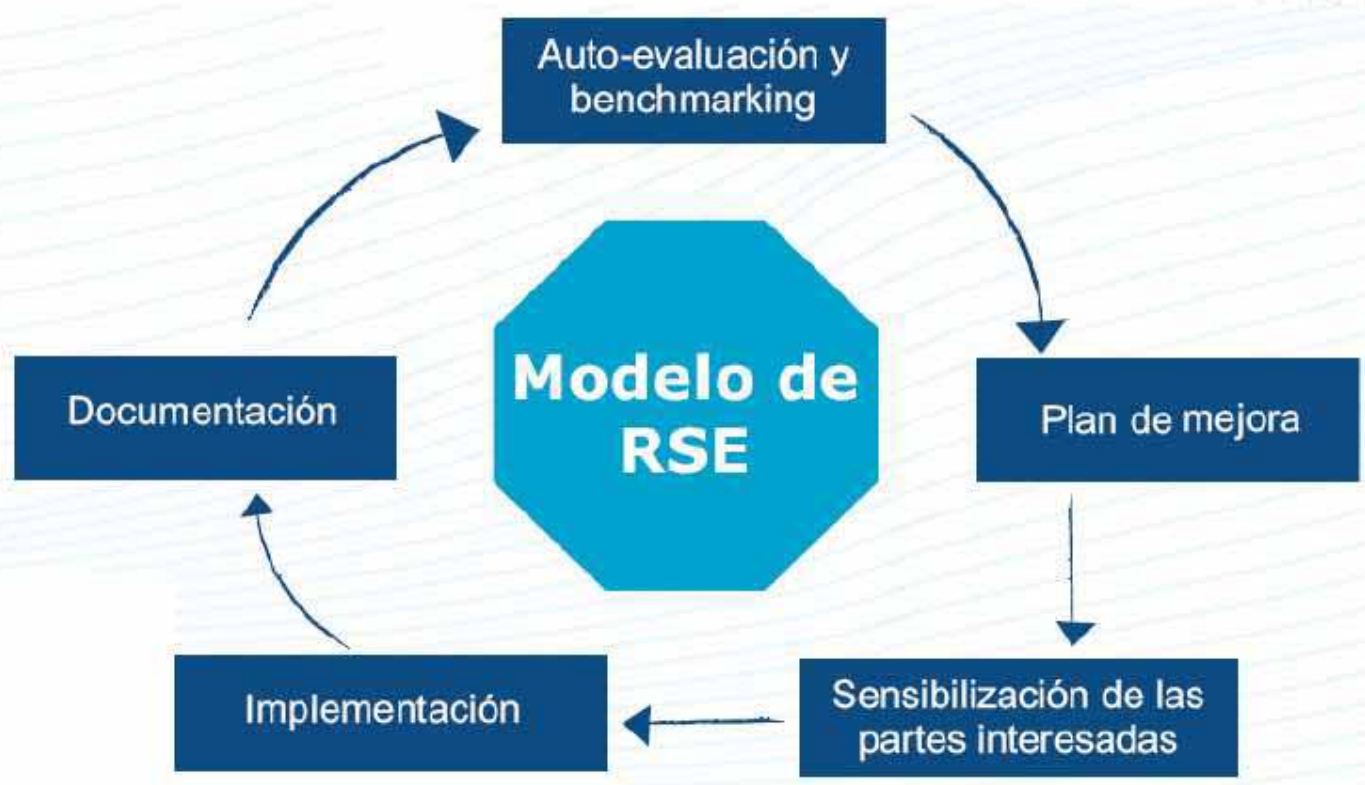

\section{Memoria anual}

AED rindió cuentas de gestión en el año 2006, con su memoria anual, de 32 páginas de extensión, la alcance de todos los interesados en su respectiva página web.

\section{Benchmarking}

En el 2005, 7 empresas costarricenses (entre ellas algunas de las más grandes del país) llevaron a cabo un riguroso proceso de auto-evaluación de sus prácticas de responsabilidad social con base en el Manual de Indicadores del Modelo de RSE para Costa Rica; estos procesos permitieron el desarrollo del primer sistema de benchmarking de RSE para Costa Rica Con este sistema, las empresas han podido comparar, de forma totalmente confidencial, sus prácticas de RSE con otras empresas que han venido desarrollando prácticas socialmente responsables desde hace varios años.

\section{Empresas participantes en el 2006 Empresas participantes en el 2007}


Atlas Industrial

Banco Banex (actualmente HSBC)

Coopagrimar R.L.

Banco Nacional de Costa Rica

Florida Bebidas

British American Tobacco Central America

Grupo Nación

Café Britt

SC Johnson de Centroamérica

Florida Bebidas

TotalPet S.A.

Grupo Nación

WPP Continental de Costa Rica

Kimberly Clark Resintech

SC Johnson de Centroamérica

\section{Cursos Intensivos}

Dentro de los productos de AED, esta la formación de personal que lidere e implemente el proceso hacia el fortalecimiento de la RSE en la gestión empresarial. En conjunto con sus alianzas estratégicas o por su mismo capital humano, brinda distintos cursos intensivos y seminarios a todos los "Stakeholders" que les interese tener más conocimiento sobre responsabilidad social. 


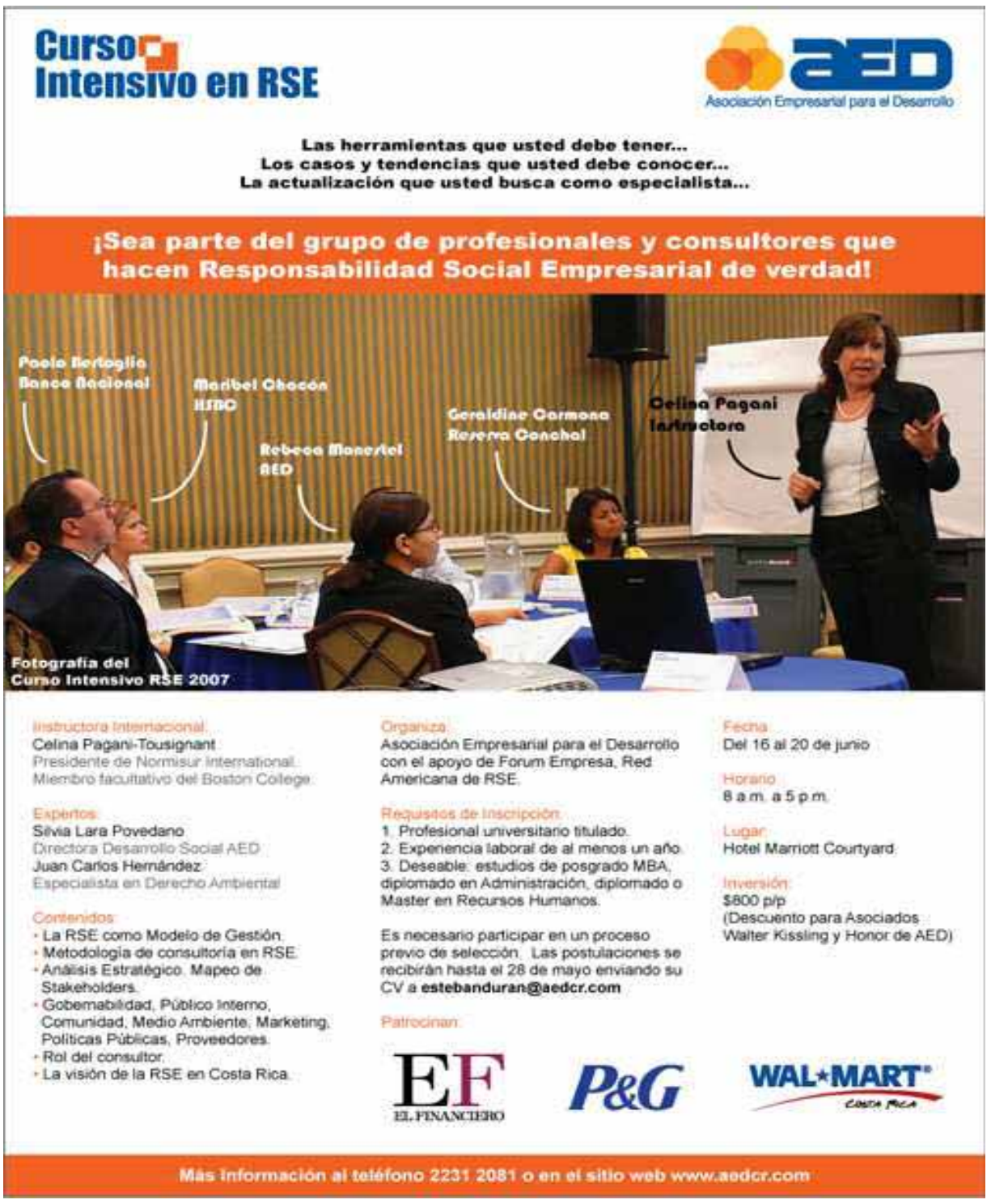

RSE CONSULTORES: CECILIA MORA

El fortalecimiento institucional de las empresas también aplica a las asociaciones o empresas que ofrecen el servicio de consultoría en temáticas como Responsabilidad Social. Cecilia Mora es una consultora de la empresa RSE Consultores, graduada de la Universidad de Costa Rica y con experiencia laboral en AED, Cecilia ha sido parte de las grandes pioneras y actores sociales en el desarrollo y reto de la responsabilidad social en las empresas.

Dentro de su agenda, tiene como proyecto a Horizontes, empresa seleccionada para el análisis de lo teórico y práctico, en la cual ha brindado asesoría en términos de Responsabilidad Social. 


\section{Para citar este artículo:}

